\title{
Assessment of the tropical Indo-Pacific climate in the SINTEX CGCM
}

\author{
Silvio Gualdi $\left({ }^{1}\right)$, Antonio Navarra $\left({ }^{1}\right)$, Eric Guilyardi $\left({ }^{2}\right)\left({ }^{*}\right)$ and Pascale Delecluse $\left({ }^{2}\right)$ \\ ${ }^{1}$ ) Istituto Nazionale di Geofisica e Vulcanologia, Bologna, Italy \\ ${ }^{2}$ ) Laboratoire d'Océanographie Dynamique et de Climatologie, Unité Mixte de Recherche CNRS-IRD-UPMC, \\ Université Pierre et Marie Curie, Paris, France
}

\begin{abstract}
A new coupled GCM (SINTEX) has been developed. The model is formed by the atmosphere model ECHAM-4 and the ocean model ORCA. The atmospheric and oceanic components are coupled through OASIS. The domain is global and no flux correction is applied. In this study, we describe the ability of the coupled model to simulate the main features of the observed climate and its dominant modes of variability in the tropical Indo-Pacific. Three long experiments have been performed with different horizontal resolution of the atmospheric component in order to assess a possible impact of the atmosphere model resolution onto the simulated climate. Overall, the mean state is captured reasonably well, though the simulated SST tends to be too warm in the tropical Eastern Pacific and there is a model tendency to produce a double ITCZ. The model gives also a realistic representation of the temperature structure at the equator in the Pacific and Indian Ocean. The slope and the structure of the equatorial thermocline are well reproduced. Compared to the observations, the simulated annual cycle appears to be underestimated in the eastern equatorial Pacific, whereas a too pronounced seasonal variation is found in the Central Pacific. The main basic features of the interannual variability in the tropical Indo-Pacific region are reasonably well reproduced by the model. In the Indian Ocean, the characteristics of the simulated interannual variability are very similar to the results found from the observations. In the Pacific, the modelled ENSO variability appears to be slightly weaker and the simulated period a bit shorter than in the observations. Our results suggest that, both the simulated mean state and interannual variability are generally improved when the horizontal resolution of the atmospheric model component is increased.
\end{abstract}

Key words coupled models - climate variability tropics

\section{Introduction}

It is widely accepted that the climate and its variability are the result of a complex system of air-sea interactions and atmosphere-ocean feedbacks. Therefore, Coupled General Circulation ocean-atmosphere Models (CGCMs) are

Mailing address: Dr. Silvio Gualdi, Istituto Nazionale di Geofisica e Vulcanologia, Via Gobetti 101, 40129 Bologna; e-mail: gualdi@ingv.it

(*) Present affiliation: Centre for Global Atmospheric Modelling, University of Reading, U.K. needed in order to simulate and to investigate the phenomena that characterize the climate system and its main modes of variability.

Mostly due to improvements in the parametrization schemes, both ocean and atmosphere general circulation models have nowadays reached a notable ability in simulating the observed climate (e.g., Gates et al., 1998; Stockdale et al., 1998). However, small errors in the formulation of the model components, which appear to be unimportant when the atmospheric or the oceanic components are integrated in uncoupled mode, may be amplified in coupled experiments due to positive air-sea feedbacks. Thus, both the mean state and the variability of a CGCM may be rather different from the observed climate (Mechoso et al., 1995; Fischer and Navarra, 2000). 
Since the pioneering work on coupling models (e.g., Manabe and Bryan, 1969; Washington et al., 1980), a number of CGCMs have been developed and are currently in use worldwide (e.g., Achuta Rao et al., 2001). Nevertheless, this is still an area under development, and CGCMs are still in a relatively early stage. Furthermore, most of the models exhibit similar problems and deficiencies. For example: a marked tendency to produce a double Inter-Tropical Convergence Zone (ITCZ); a poor representation of the annual cycle of the sea-surface temperature in the Tropics and a substantial underestimation of the ENSO-like variability (Mechoso et al., 1995; Delecluse et al., 1998; Achuta Rao et al., 2001). Therefore, in order to identify the reasons for these common error features, and to improve our general understanding of the climate system, it is important to have a variety of different models. In this framework, a detailed investigation and comparison of the behaviour of CGCMs that share common components (for example the same ocean model coupled with different atmospheric models) is of crucial importance. Furthermore, the impact of model resolution needs also to be investigated.

In this paper, we present a new coupled atmosphere-ocean general circulation model. The model has been developed in the framework of the Scale INTeraction EXperiment (SINTEX) European Union project, and for this reason it has been named the SINTEX model. SINTEX is formed by the atmospheric component ECHAM4 (Roeckner et al., 1996) and ocean component ORCA (Madec et al., 1998) without an interactive sea-ice model. The coupler is OASIS (Valcke et al., 2000), and no flux-correction is applied.

Examples of other CGCMs that use ECHAM4 as atmospheric component are ECHO-2 (Frey et al., 1997) and ECHAM-4/OPYC3 (Bacher et al., 1998). ORCA, on the other hand, is the ocean component of a number of coupled models, like for example the OPA/ARPEGE model (Guilyardi and Madec, 1997) and the HadAM3/ OPA model (Inness et al., 2003).

The main objective of this study is to assess to which extent the SINTEX model is able to simulate the gross general features of the observed climate and climate variability. We focus, in particular, on the tropical region, analyzing the capability of the model to reproduce the main modes of variability observed in this region. Two companion studies investigate in detail the mechanism of the interannual variability in the equatorial Pacific (Guilyardi et al., 2003) and Indian Ocean (Gualdi et al., 2003).

Furthermore, in order to assess the impact of increased atmospheric resolution onto the coupled system, we used ECHAM-4 with three different horizontal resolutions: T30, T42 and T106. Stendel and Roeckner (1998) have analyzed the sensitivity of the ECHAM-4 model to changes in horizontal resolution, using simulations performed with observed sea-surface temperature as lower boundary conditions. Their results indicate that increased resolution will not automatically reduce the systematic model error, and the T30, T42 and T106 simulations are similar in many respects. However, they show also that a more realistic orography helps to improve the simulation of the zonally asymmetric component of the circulation (stationary waves), as well as, it has a positive impact on regional precipitation patterns. In this study, we are interested in analyzing the impact of increased atmospheric resolution on the coupled air-sea processes.

The paper is organized as follows: in Section 2 , the model is described. In Section 3, we describe the experiments performed with the model and the data analyzed. Section 4 examines the observed and simulated climatology. The simulated interannual variability is described in Section 5. In Section 6, a summary and some discussion complete the paper.

\section{The SINTEX model}

The model used for this study is the ECHAMORCA coupled GCM developed within the SINTEX (Scale INTeraction EXperiment) EU project.

\subsection{The oceanic component ORCA}

ORCA is the global version of the OPA 8.1 ocean modeling system developed by the 
LODYC team in Paris (Madec et al., 1998, see full documentation at http://www.lodyc.jussieu.fr/ opa/). It is a finite differences OGCM and solves the primitive equations with a non-linear equation of state on an Arakawa C-grid.

The present configuration uses a rigid lid. The horizontal mesh is orthogonal and curvilinear on the sphere. To overcome the singularity at the North Pole, the northern point of convergence has been replaced by two poles located on Asia and North America. Its space resolution is roughly equivalent to a geographical mesh of 2 by 1.5 degrees (with a meridional resolution of 0.5 degrees near the Equator). 31 vertical levels are used with 10 levels in the top $100 \mathrm{~m}$.

Vertical eddy diffusivity and viscosity coefficients are computed from a 1.5 turbulent closure scheme which allows an explicit formulation of the mixed layer as well as minimum diffusion in the thermocline (Blanke and Delecluse, 1993). Horizontal mixing of momentum is of Laplacian type with an eddy viscosity coefficient of $40000 \mathrm{~m}^{2} / \mathrm{s}$, reduced in the Tropics to reach $2000 \mathrm{~m}^{2} / \mathrm{s}$ at the Equator. The lateral mixing of tracers (temperature and salinity) is «quasi-pure» isopycnal as described by Guilyardi et al. (2001).

There is no interactive sea-ice model in the configuration used for the present study: seaice cover is relaxed towards observed monthly climatology.

\subsection{The atmospheric component ECHAM-4}

ECHAM-4 is the fourth generation of the ECHAM Atmospheric General Circulation Model (AGCM) developed at the Max Planck Institut Für Meteorologie in Hamburg. ECHAM is an evolution of the spectral numerical weather prediction model developed at the European Center for Medium-Range Weather Forecasting (ECMWF), but significantly modified to make it suitable for climate studies. In the successive model generations, several parametrization schemes were either replaced or additionally implemented.

An exhaustive and detailed description of the dynamical and physical structure, and the simulated climatology of ECHAM-4 has been given by Roeckner et al. (1996). Here we summarize briefly the main characteristics of the model. The prognostic variables in ECHAM-4 include vorticity, divergence, temperature, surface pressure, water vapor and cloud water. The model equations are solved on 19 hybrid vertical levels (top at $10 \mathrm{hPa}$ ) by using the spectral transform method.

ECHAM-4 uses a semi-Lagrangian transport method for the advection of cloud water and water vapor (Rasch and Williamson, 1990). The parameterization of convection is based on the mass flux concept, where cumulus clouds are represented by a bulk model including the effects of entrainment and detrainment on the updraft and downdraft convective mass fluxes (Tiedtke, 1989). According to Nordeng (1994), the organized entrainment and detrainment are related to buoyancy and an adjusted-type closure based on the Convective Available Potential Energy (CAPE) is used. The radiation code is the same as Morcrette (1991) with a few modifications such as the inclusion of additional greenhouse gases, revised parametrization for the water vapor continuum and for the cloud optical properties.

\subsection{The coupling procedure}

The atmospheric and oceanic components have been coupled through OASIS 2.4 (Valcke et al., 2000).

The coupling strategy has been described in Guilyardi et al. (2001): starting from the Levitus climatology (Levitus, 1982) as initial conditions, the ocean component has been integrated for 2 years in ocean robust-diagnostic mode. The initial conditions for the atmospheric component were obtained from an experiment with the atmospheric model forced with climatological Sea-Surface Temperature (SST). Once the ocean dynamics was spun-up, the integration was carried on without any adjustment nor restoring (except in regions where sea-ice cover did not agree with climatology).

In order to properly resolve the diurnal cycle, air-sea fluxes and SST were exchanged between the model components every $3 \mathrm{~h}$. 


\section{The analyzed data and the model experiments}

In order to investigate the possible impact of the horizontal resolution of the atmospheric component onto the simulated climate, we implemented three different versions of the SINTEX model. The same ocean component has been coupled with the atmospheric model at different horizontal resolution: a low-resolution version with a triangular truncation at wavenumber 30 (T30); a medium-resolution version with a triangular truncation at wave-number 42 (T42) and a high-resolution model with a triangular truncation at wave-number 106 (T106).

Two long experiments (200 years) have been performed with the T30 and T42 atmosphere component. A third long run, with the highresolution T106 model, has been performed for 70 years. In this paper, we show results obtained from the entire 200-year integration for the T30 and T42 models, and from the 70 years available for the T106 experiment.

Despite the short spin-up, the drifts at the atmosphere-ocean interface are reasonably small. As an example, fig. 1 shows the inverse trend of the SST zonally averaged over the globe for the low-resolution (T30) version of the model. The trend is shown as a time-latitude diagram, and it has been computed as the SST anomaly with respect to the mean obtained from the last 5 years of integration. Therefore, negative values indicate a positive (warm) SST trend. The result shown in fig. 1 is fairly representative of the general behavior of the model at all the resolutions. The global SST exhibits a slight warm trend localized at high latitudes, whereas it is practically absent in the Tropics. The Sea-Surface Salinity (SSS) exhibits a drift with similar patterns. The largest SSS drift is found at the high latitudes and especially in the North Atlantic likely associated with the lack of interactive sea-ice.

The model results are compared with the results obtained from the NCEP (National Centers for Environmental Predictions) re-analysis (Kalnay et al., 1996), the Levitus climatology (Levitus, 1982) and the HadISST1.1 Global SeaIce and Sea-Surface Temperature (Rayner et al., 2000) data set (hereafter GISST). The simulated precipitation is compared with the precipitation fields obtained from the Xie-Arkin data set (1996).

\section{The model climatology}

\subsection{Global features}

The climatological SST patterns derived from the GISST data set and the models are shown in fig. 2a-h. Panels a-d show the January-February-

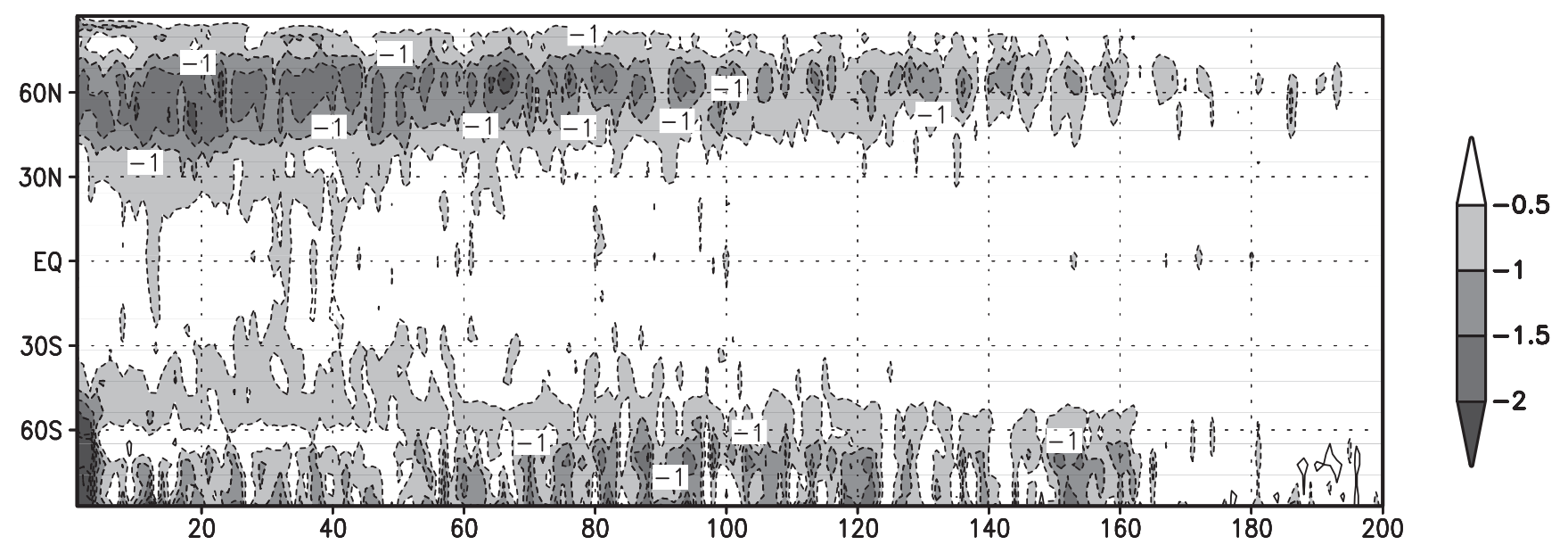

Fig. 1. Inverse trend of the SST zonally averaged obtained from the T30 experiment. The trend is computed with respect to the last 5-year mean, therefore negative values indicate a positive (warm) SST trend. Dashed contour lines and shaded areas indicate negative values. Contour interval is $0.5^{\circ} \mathrm{C}$. 
(a)

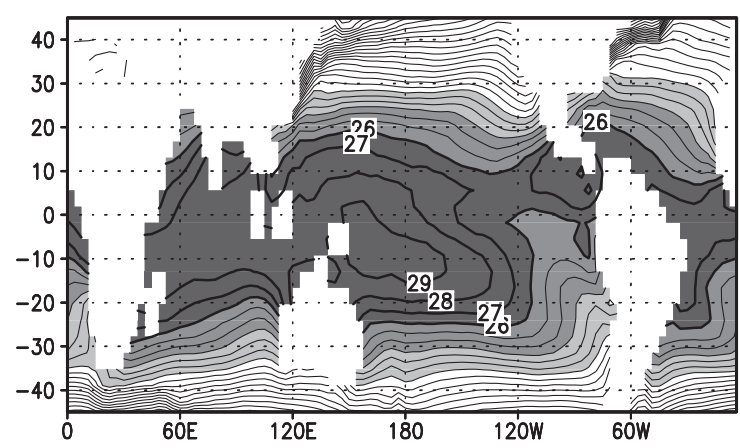

(C)

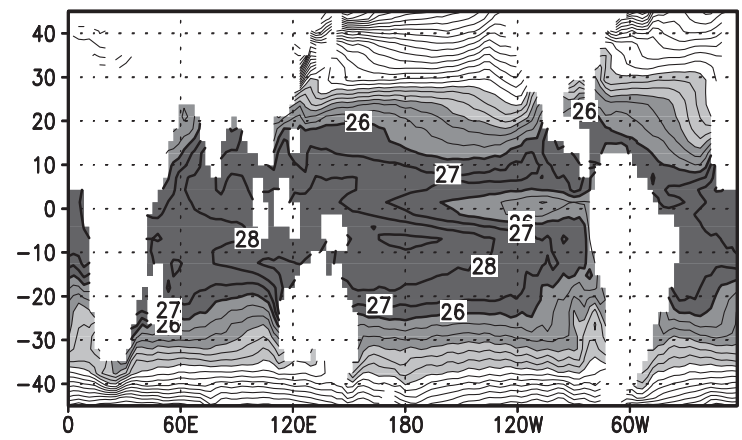

(e)

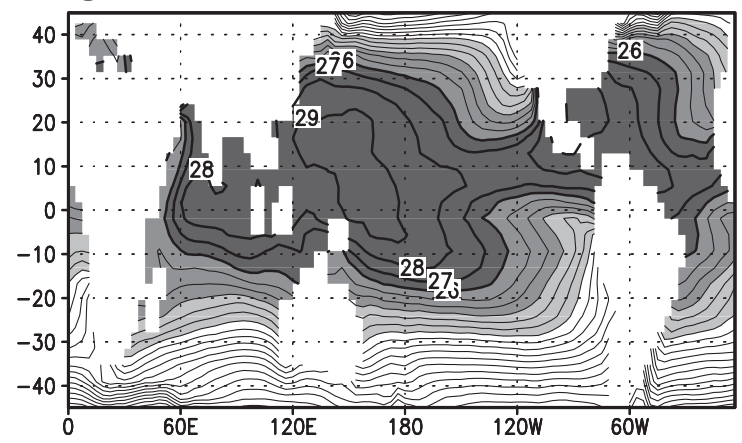

(9)

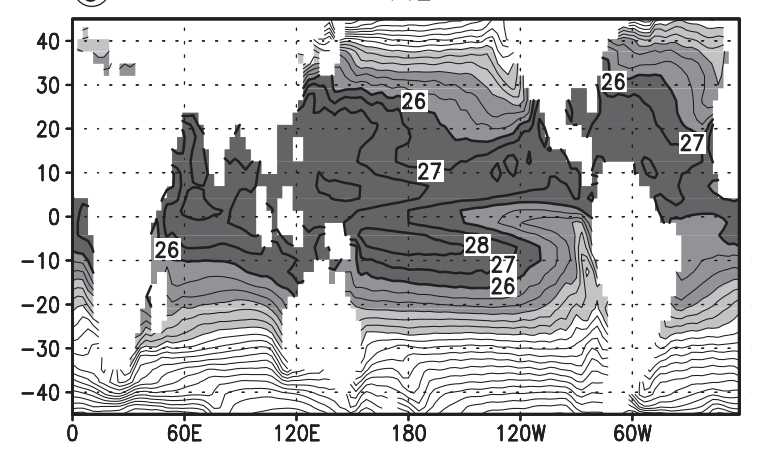

(b)

T106

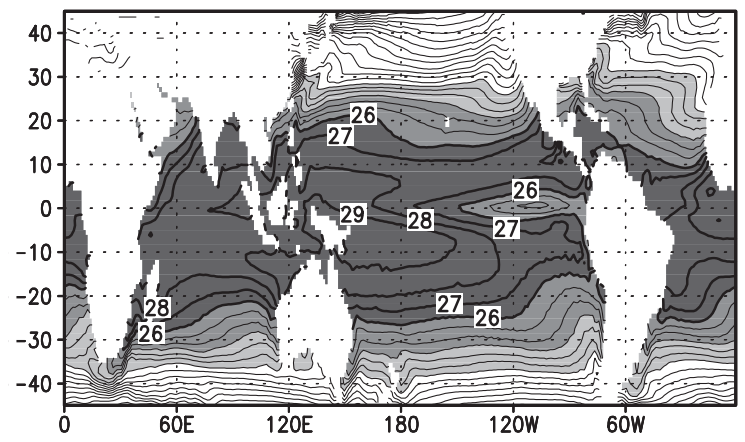

(d)

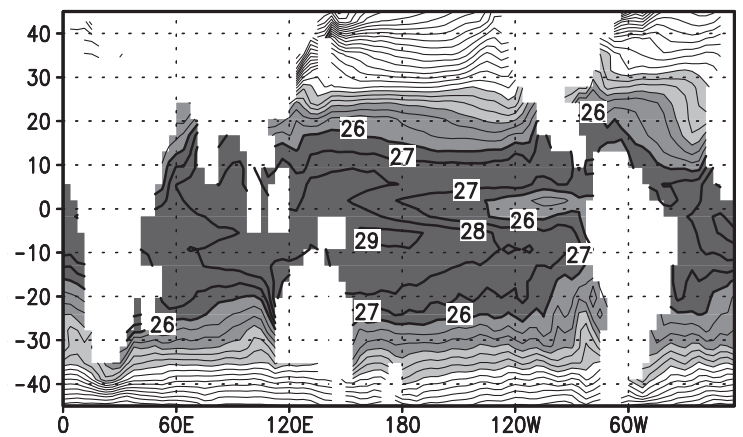

(

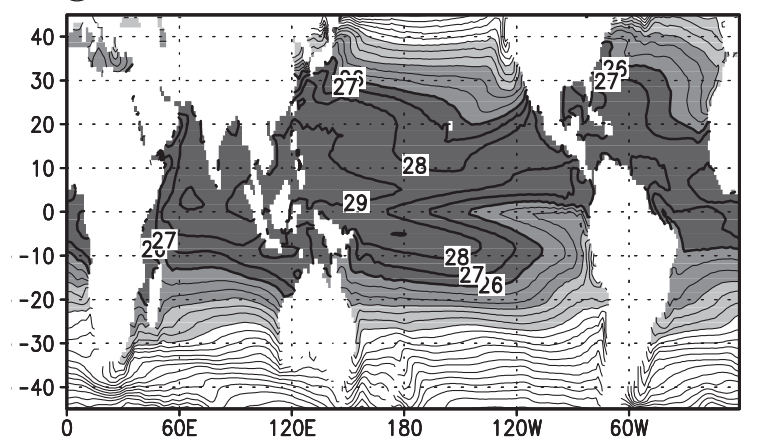

(h)

T30

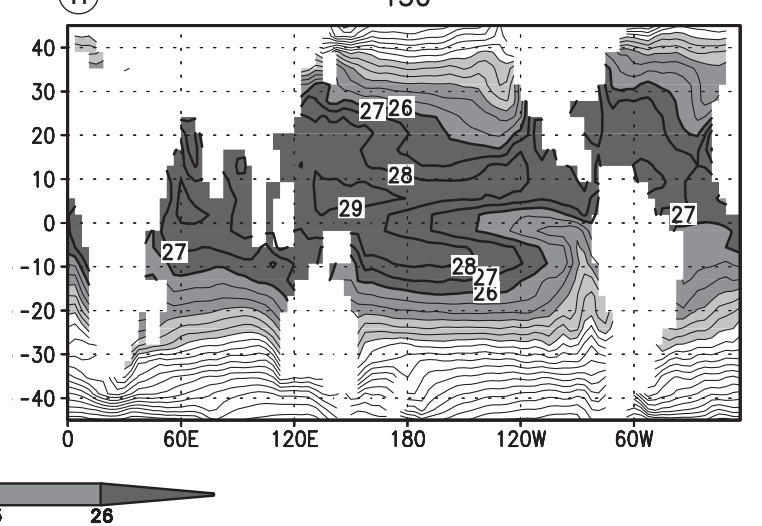

Fig. 2a-h. Mean SST fields. Panel a) and panel e), as derived from the GISST data set for the northern winter (JFM) and northern summer (JAS) respectively; panel b) and panel f), as derived from the T106 experiment for JFM and JAS respectively; panel c) and panel g), as derived from the T42 experiment for JFM and JAS respectively; panel d) and panel $\mathrm{h}$ ), as derived from the T30 experiment for JFM and JAS respectively. Contour line interval is $1^{\circ} \mathrm{C}$; shaded contour interval is $3^{\circ} \mathrm{C}$. 
(a)

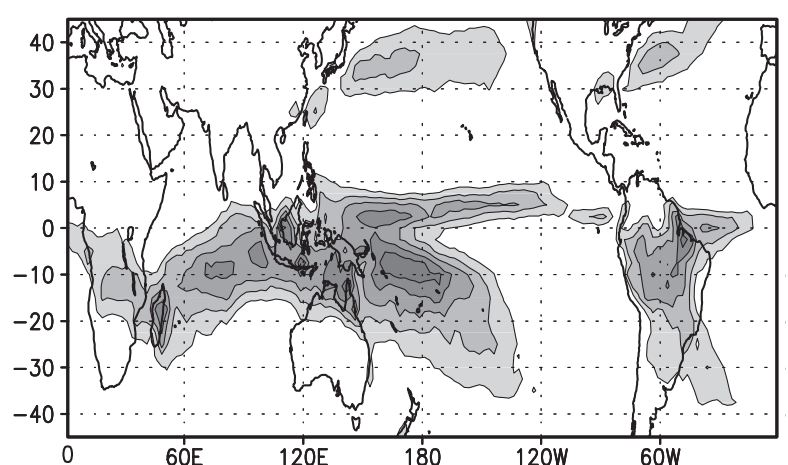

(C)

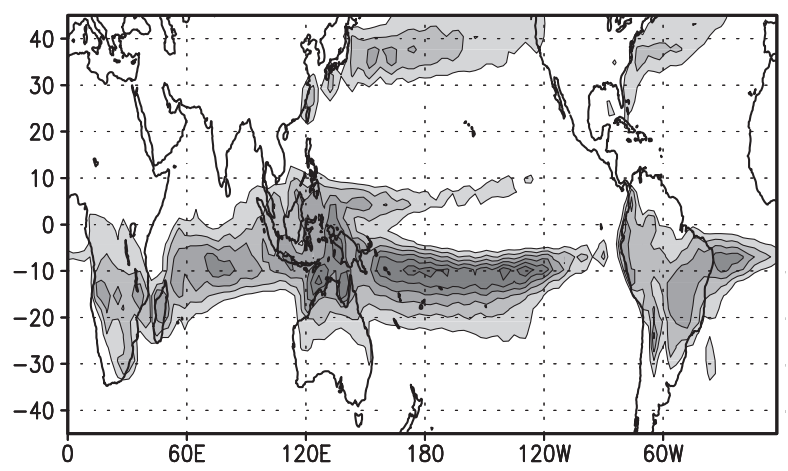

(e)

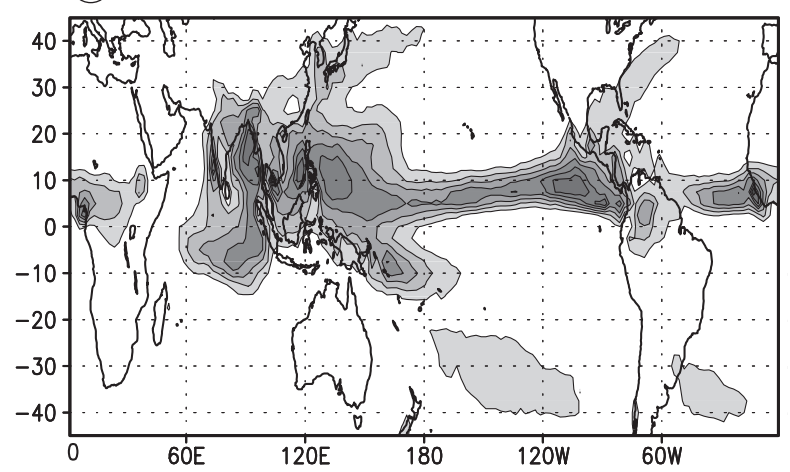

(9)

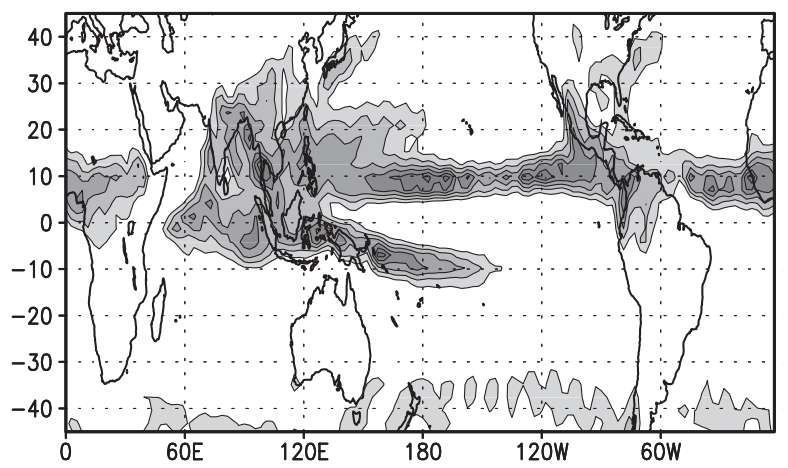

(b)

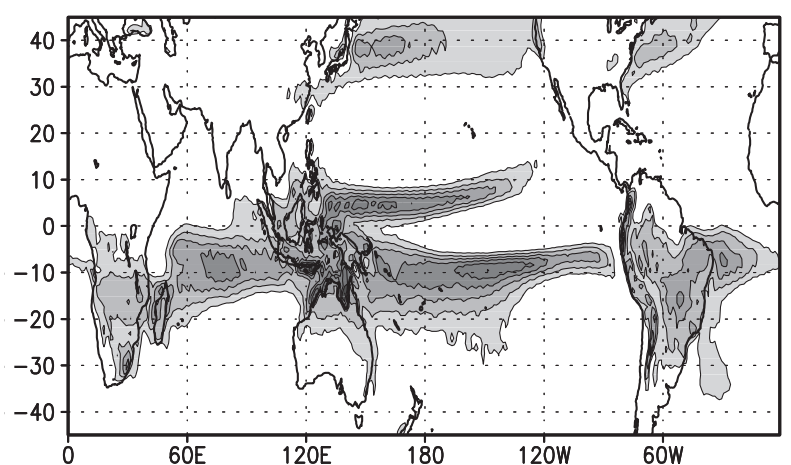

(d)

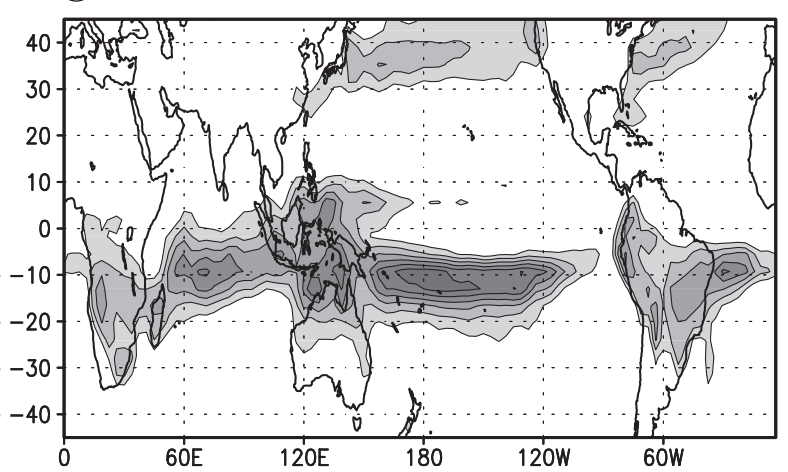

(f)

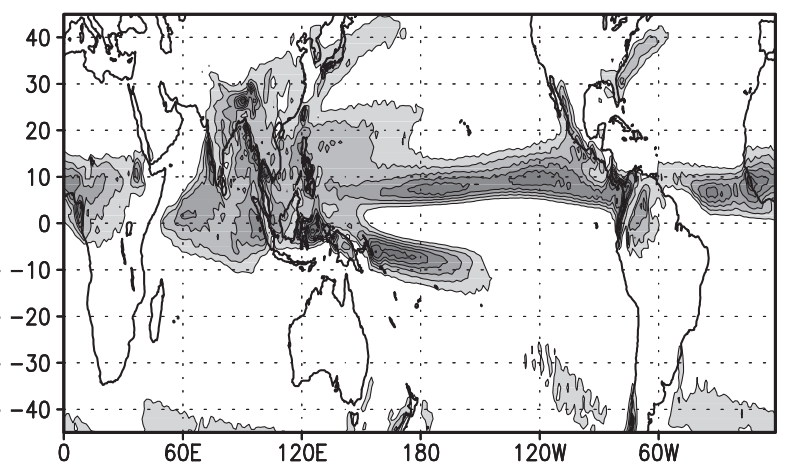

(h)
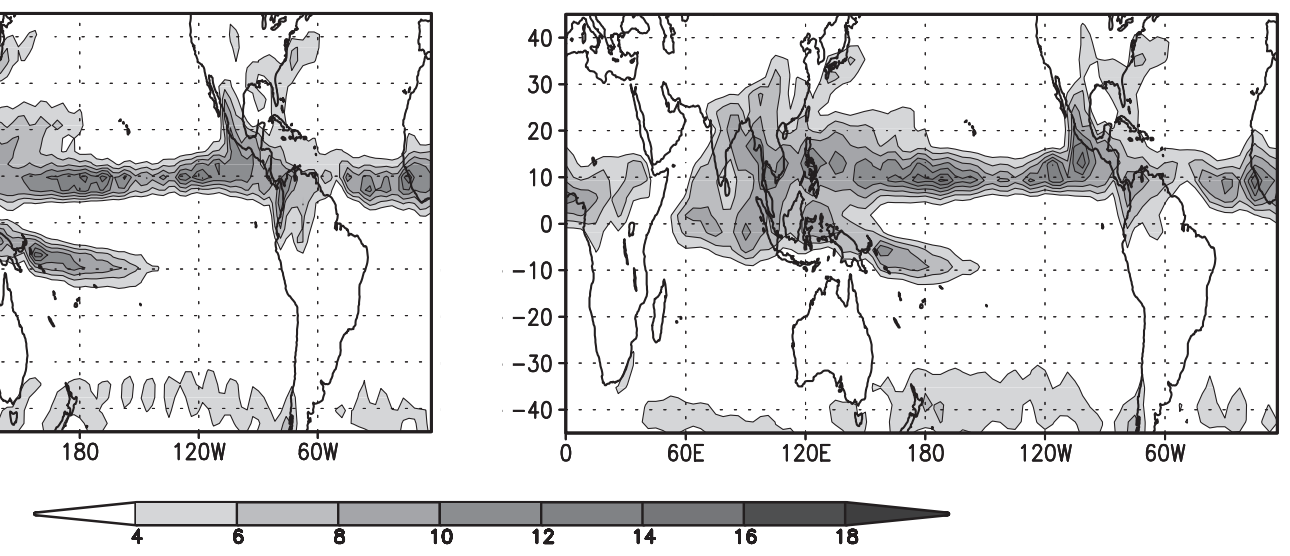

Fig. 3a-h. Same as fig. 2a-h, but for mean precipitation. Contour interval is $2 \mathrm{~mm} /$ day. Values larger than $4 \mathrm{~mm} /$ day are shaded. 
March (JFM) means; panels e-h show the JulyAugust-September (JAS) means.

Overall, the models seem to be slightly too cold in the Extra-Tropics, especially in the Central Pacific and Atlantic, and in tropical Western Pacific. However, coastal up welling regions, in the eastern part of the basins, are often underestimated. Moreover, in the Central and Eastern South Pacific, the models tend to be too warm. The cold tongue penetrates too far into the West Pacific and the SST patterns are too much symmetrical around the equator. This is a common feature of many coupled GCMs, which might be related to an inadequate representation of atmospheric convection and to the underestimated model cloud coverage (not shown) off the Peruvian coast (Terray, 1998; Fischer and Navarra, 2000). The latter, in particular, could affect the SST distribution through air-sea interactions and SST surface wind feedback mechanisms, as suggested by Fischer and Navarra (2000).

Important differences, however, can be noticed between the SST patterns produced by the different model versions. In particular, the T106 model (panel b and panel e) seems to reproduce a more realistic SST mean field both in the Western Pacific warm pool and in the Indian Ocean, especially during the northern winter.

Figure 3a-h shows the climatological precipitation as obtained from the Xie-Arkin data set (panel a for JFM and panel b for JAS) and the mean fields obtained from the models (panels b-d for JFM and panels f-h for JAS). During the northern winter, the observed precipitation exhibits a large belt of high values which extends from the tropical Africa, over the Southern Indian Ocean, Indonesian region and Northern Australia, up to the Southern Pacific Convergence Zone (SPCZ). A second region of intense precipitation is found over the tropical South America, extending eastward along the equator. Between the equator and about $10^{\circ} \mathrm{N}$, a zonal band of intense precipitation extends over most of the Pacific and the Atlantic Inter-Tropical Convergence Zone (ITCZ), with an interruption over the Eastern Pacific and equatorial America. At higher latitudes, the signature of the storm tracks is visible over both the Central-Western Pacific and Atlantic oceans.
At all resolutions, the model seems to reproduce a reasonably realistic winter precipitation over the extra-tropical oceans in the Northern Hemisphere, and over the tropical Africa, Indian Ocean and Indonesian region. Also over South America, the simulated patterns seem to capture the main basic features of the observed field, though the models tend to shift slightly southward the maximum observed over the Brazilian Nordeste and the equatorial western Atlantic.

In the tropical Pacific, the models exhibit important discrepancies with respect to the observations. The models, above all at low resolution, clearly overestimate the precipitation over the Central-Eastern Pacific south of the equator. Also the structure of the SPCZ is not well simulated. The models, in fact, tend to produce a sort of southern ITCZ, which lies parallel to the equator. The precipitation patterns obtained with ECHAM-4 forced with observed SSTs do not show any tendency to produce a double ITCZ in the tropical Pacific (Roeckner et al., 1996; Stendel and Roeckner, 1998). This suggests that the errors found in the coupled simulations are most likely related to the problems found in the simulated SST patterns (fig. 2a-h).

However, it is worthwhile to notice that at least some of these problems seem to be less pronounced when the horizontal resolution of the atmospheric component is increased. The winter precipitation simulated by the T106 model, in fact, is generally closer to the observations, and, in particular, the ITCZ simulated by this model version improves its structure.

During the northern summer (fig. 3, panels e-h), consistently with the seasonal cycle, patterns of intense precipitation are located north of the equator. The models appear to simulate quite well the precipitation over the ITCZ band, across the tropical Pacific and Atlantic oceans. The model precipitation over the SPCZ is now reduced in good agreement with the observations. However, the simulated rainfall is too weak over the equatorial Western Pacific, which is likely caused by the too cold SST found in this region (fig. 3a-h). Also, reasonably realistic patterns of intense rainfall are reproduced over the Congo and Amazonian basins. 
(a)

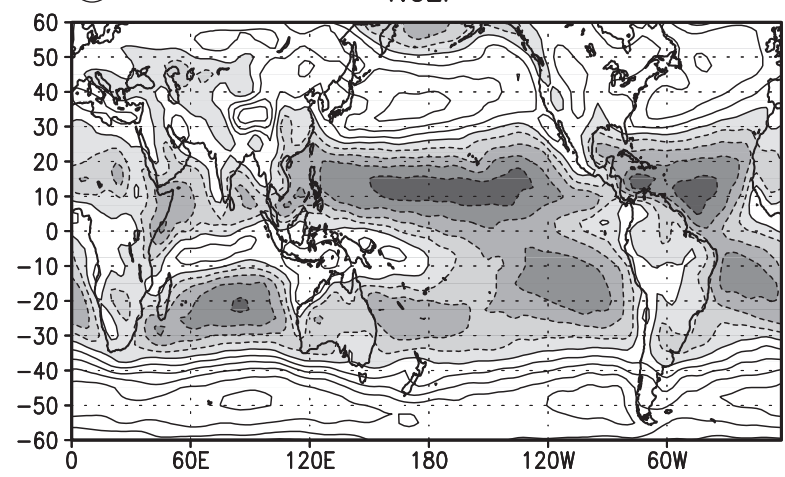

(C)

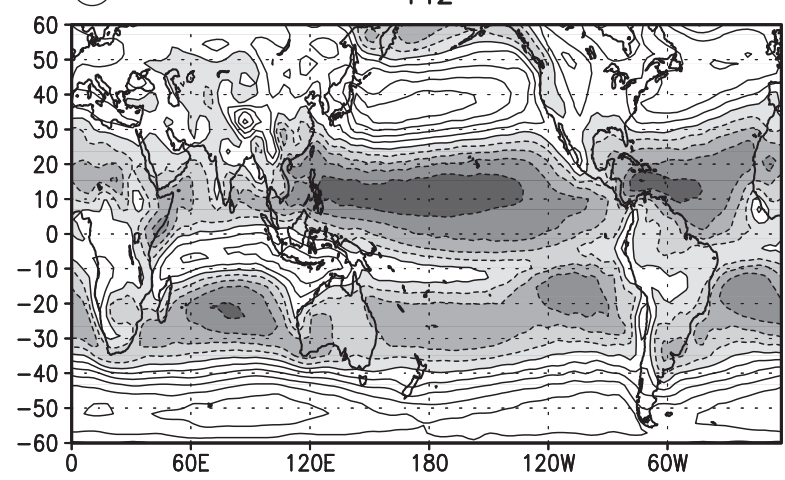

(e)

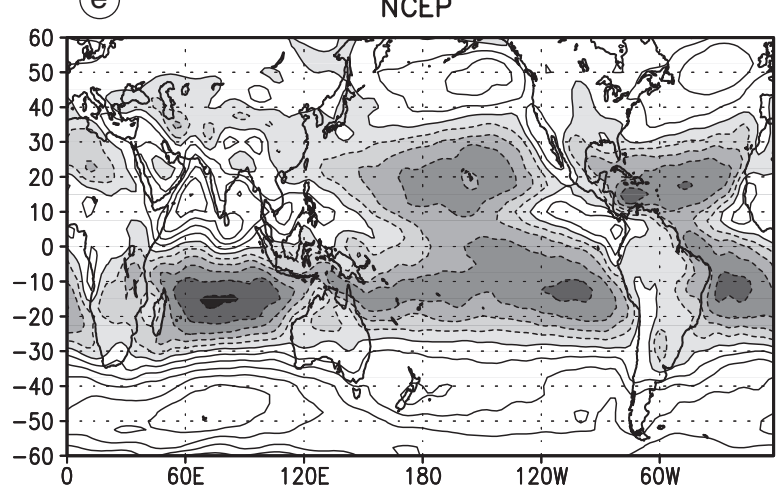

(g)

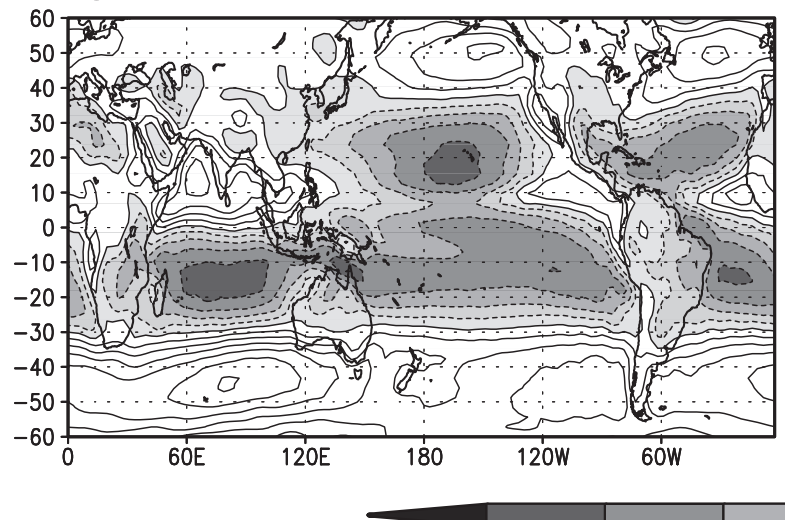

(b)

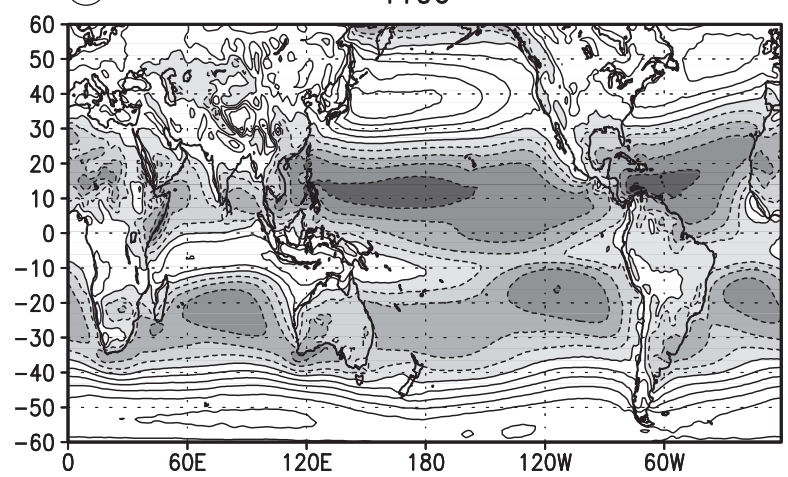

(d)

T30

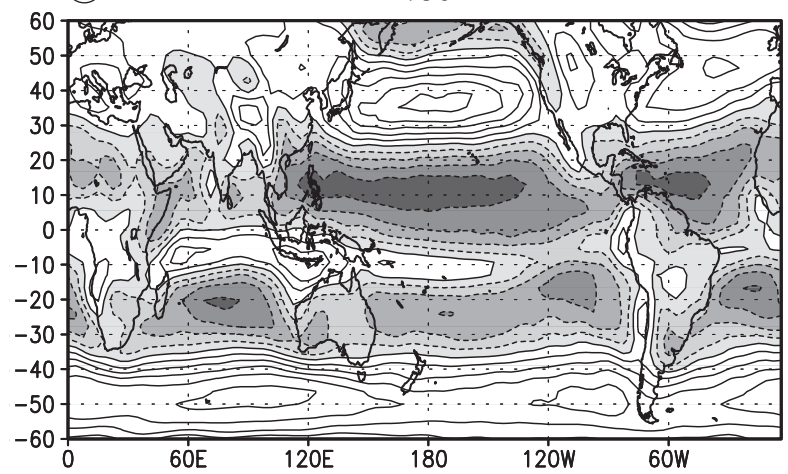

(f)

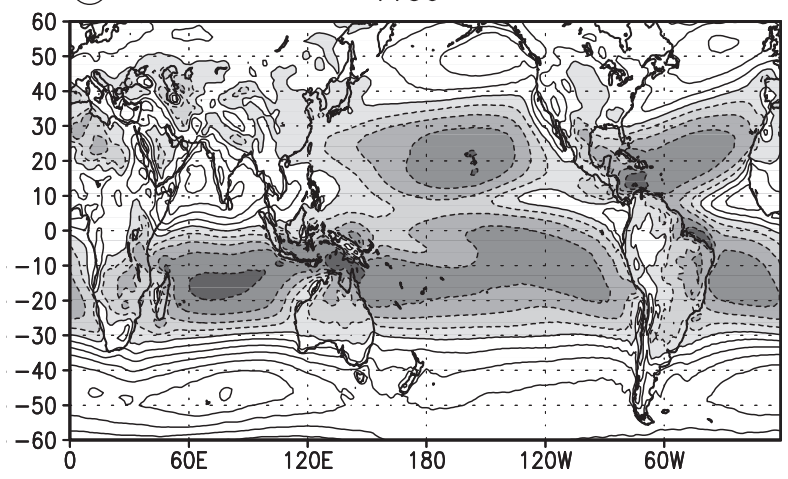

(h) T30

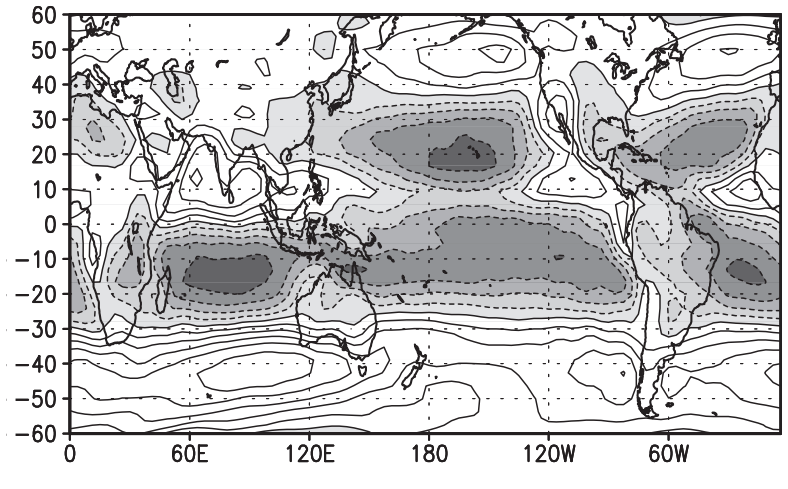

Fig. 4a-h. Same as fig. 2a-h, but for the zonal component of 1000-hPa wind. Contour interval is $2 \mathrm{~m} / \mathrm{s}$. Dashed contour lines and shaded areas indicate negative values. 
The underestimation of the Asian summer monsoon is a well-known problem of ECHAM4 (Roeckner et al., 1996). Also in the coupled experiments, the precipitation over the areas of the Asian summer monsoon activity appears to be problematic. The coupled models, at all resolutions, have problems in simulating the maxima of precipitation observed over the Bay of Bengal and over the Philippines. However, in agreement with Stendel and Roeckner (1996), the increased resolution of the atmospheric component improves some detail of the simulated precipitation related to the orographic effects. Thus, for instance, the T106 model is able to reproduce the maximum of rainfall over the Western Ghats (fig. 3, panel f).

The zonal component of the near-surface wind is shown in fig. 4 (panels a-d for JFM and panels e-h for JAS). In general, all the models are able to capture the basic features of the zonal wind structure. However, the simulated trades have a noticeable westward shift in the Northern Hemisphere and they tend to be stronger than observed, especially over the equatorial Pacific. This is probably the cause of the too pronounced equatorial cold tongue found in the simulated SSTs (fig. 2a-h).

Also in this case, the T106 model exhibits some improvement with respect to the lower resolution models. In particular, during the winter season, the wind patterns reproduced by the T106 model (fig. 4, panel b) are closer to the NCEP re-analysis (fig. 4, panel a) over the tropical Pacific, the Indian Subcontinent, and along the western coast of South America. During northern summer (fig. 4, panels e-h), the zonal component of the Somali jet is reasonably well reproduced by the models, though a bit too weak in the T30 model version.

The meridional component of the low-level wind is shown in fig. 5a-h. Both during the boreal winter (panels a-d) and boreal summer (panels e-h), the models simulate quite well the meridional wind structure over the Northern Pacific and Atlantic. The maxima of meridional surface wind, located off the continental western coasts in the Extra-Tropics, are quite realistically represented, even if the simulated field is slightly too strong off the coast of California during northern summer (panels f-h). The T30 model tends to overestimate the positive meridional wind offshore the western coast of Canada during JFM (panel d).

In the region of the Indian monsoon activity, the meridional component of the NCEP wind (panel a and panel e) exhibits a number of smallscale features. Only the higher resolution models, and in particular the T106 version, seem to be able to capture these fine structures. This result and the results found for the low-level zonal wind (fig. 4a-h) suggest that the simulation of the Indian monsoon flow is improved when the horizontal resolution of the model atmospheric component is increased.

A definite weakness of the model at all resolutions is the near-surface meridional flow over the tropical Pacific. For example, during the JFM season, the re-analysis (panel a) shows a band of relatively strong northerly wind centered at about $10^{\circ} \mathrm{N}$, which covers the entire tropical Pacific and intensifies at the eastern boundary of the ocean. All models (panels b-d) clearly exhibit two zonal bands of stronger northerly winds: one, located about $10^{\circ}$ north of the equator, and a second one lying parallel to the equator, in the Central Pacific, between the equator and about $10^{\circ} \mathrm{S}$. The structure of the simulated surface meridional flow in the tropical Pacific is clearly related to the model tendency to produce a double ITCZ, as noticed for the precipitation patterns (fig. 3a-h). The structure of the simulated low-level meridional wind exhibits some problem also over the tropical Atlantic, where the winter monsoon stays too far south compared to the observations.

Figure $6 \mathrm{a}-\mathrm{h}$ shows the mean zonal wind at 200-hPa. For the JFM season (panels a-d), the overall structure is well captured by the models. However, some differences between the reanalysis and the models are visible, for example, in the extra-tropical Pacific. Here, the simulated jet is slightly too strong and tends to extend a bit too far into the Eastern Pacific (especially for the T30 case). Moreover, the T106 model appears to underestimate the Atlantic jet over the eastern coast of the U.S.

In the models, the tropical easterlies extend too far over the Central Pacific, and they also tend to cover the entire tropical Atlantic, especially in the T106 case. 
(a)

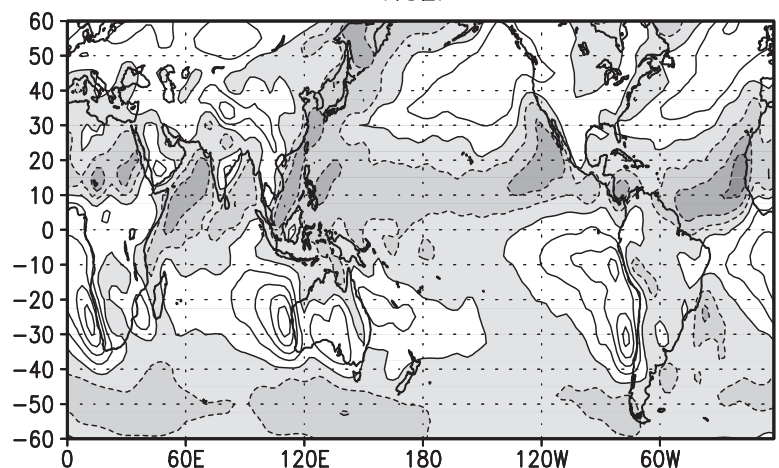

(C)

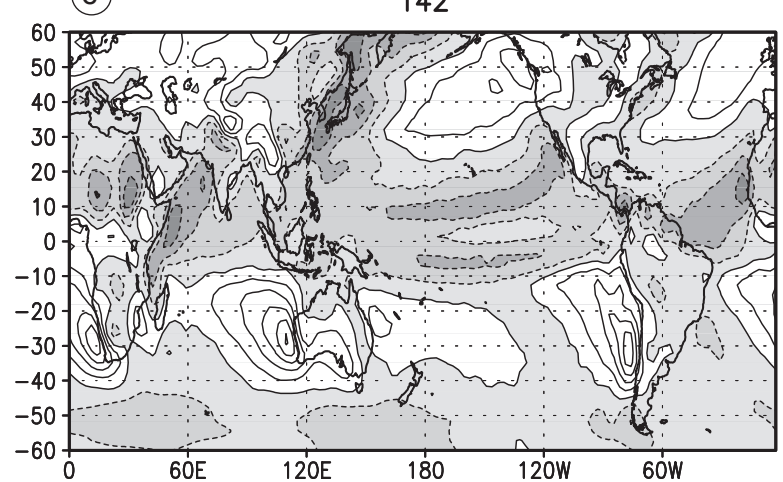

(e)

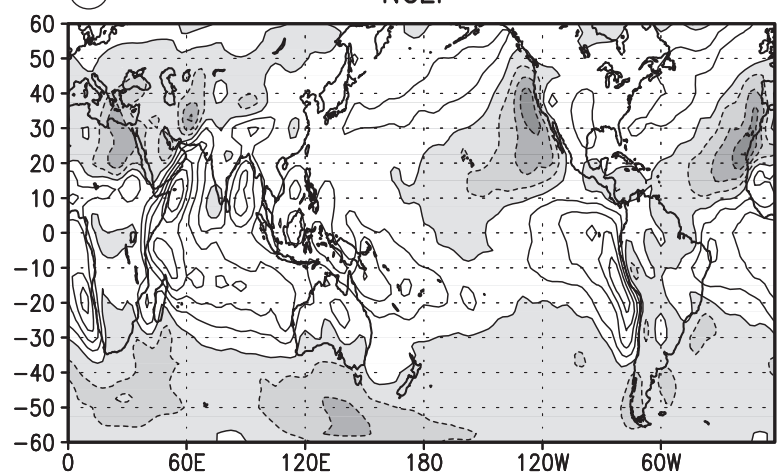

(9)

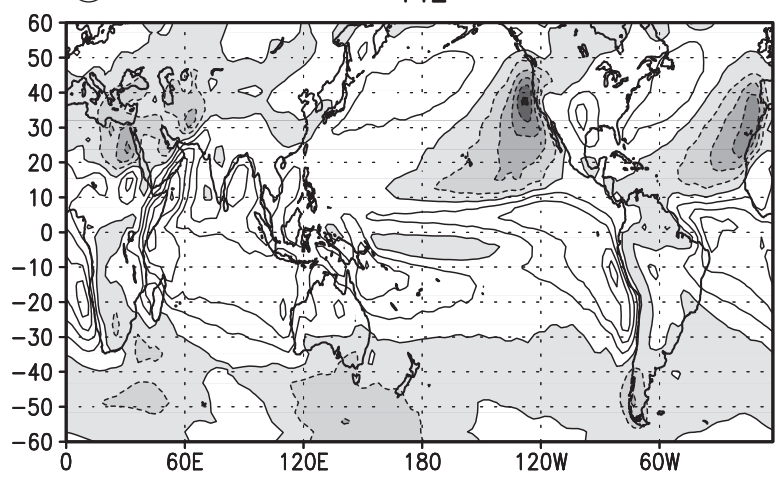

(b)

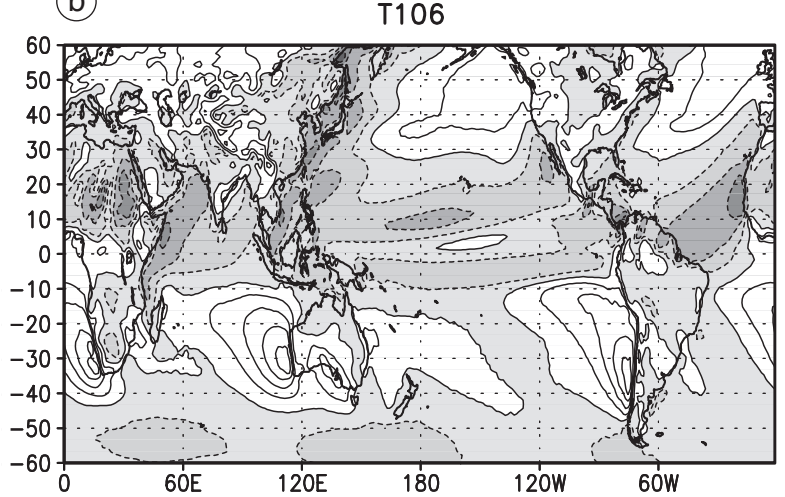

(d)

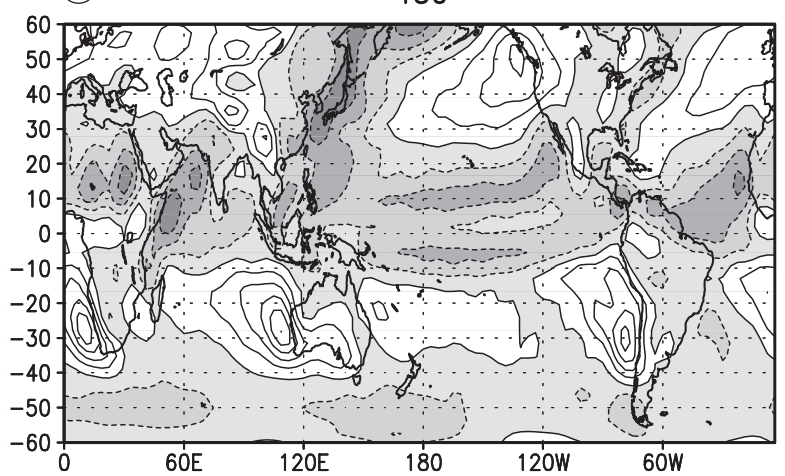

(f)

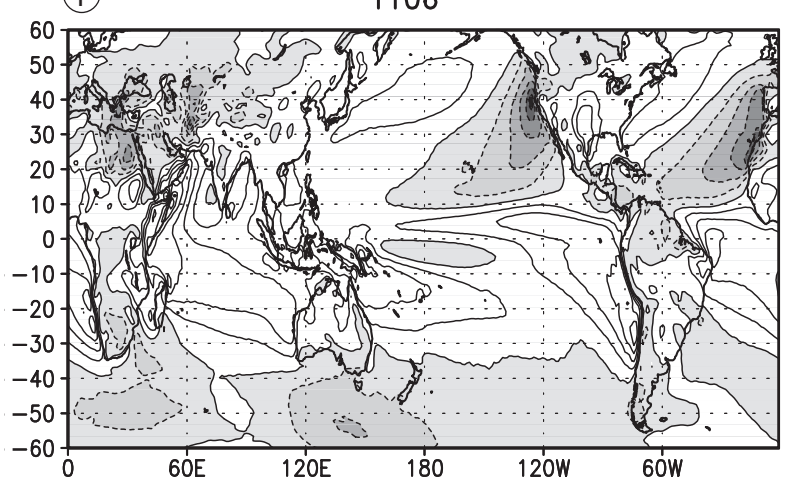

(h)

T30

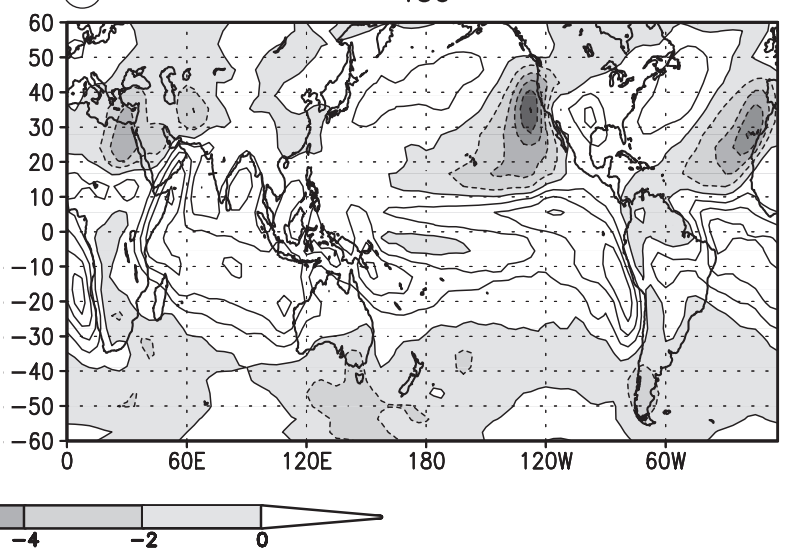

Fig. 5a-h. Same as fig. 4a-h, but for the meridional component of $1000-\mathrm{hPa}$ wind. Contour interval is $2 \mathrm{~m} / \mathrm{s}$. Dashed contour lines and shaded areas indicate negative values. 
(a)

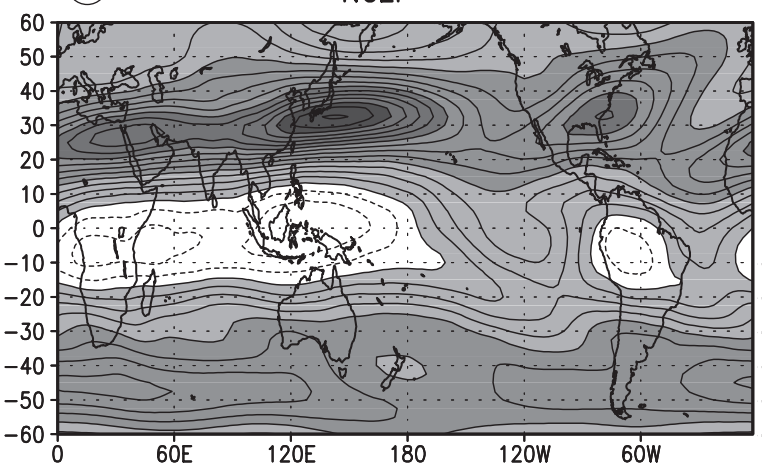

(C)

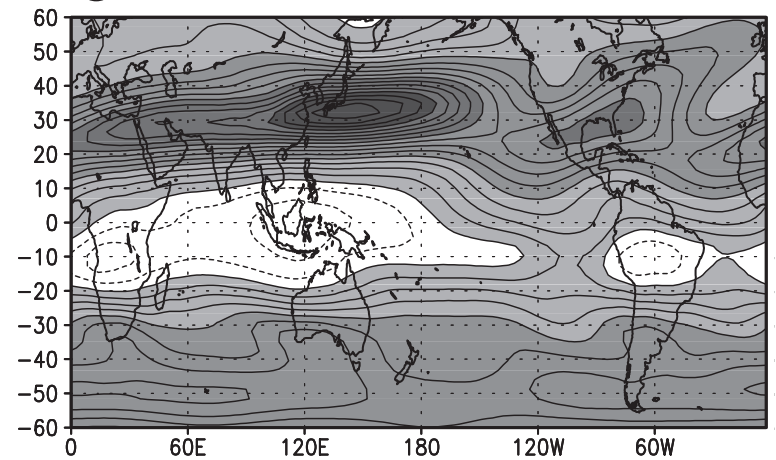

(e)

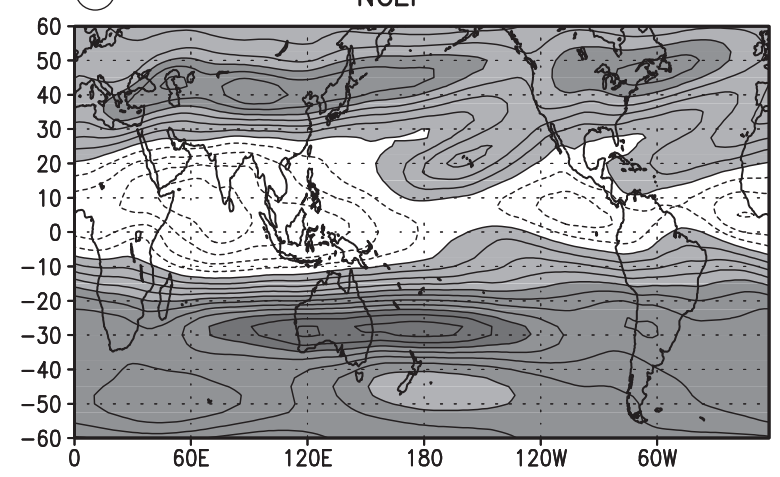

(9)

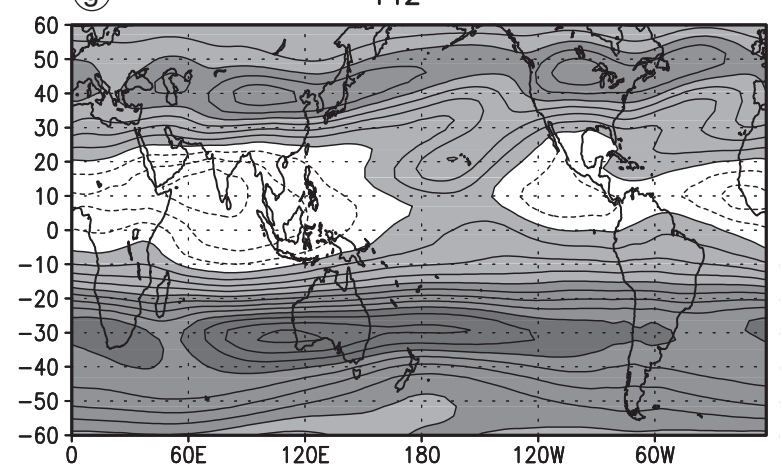

(b)

T106

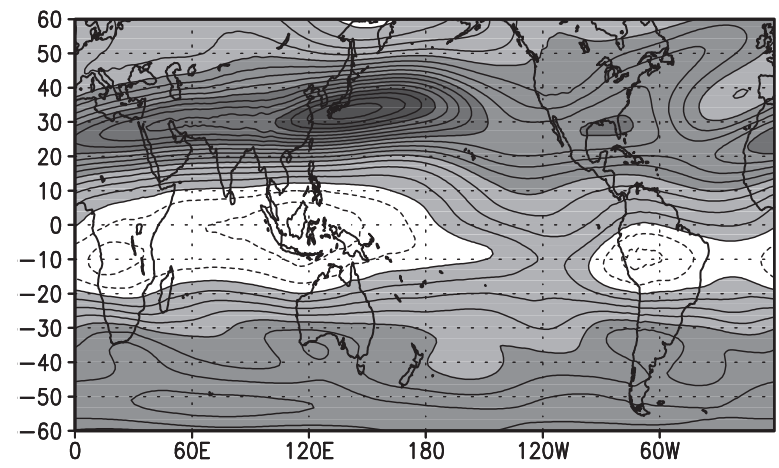

(d)

T30

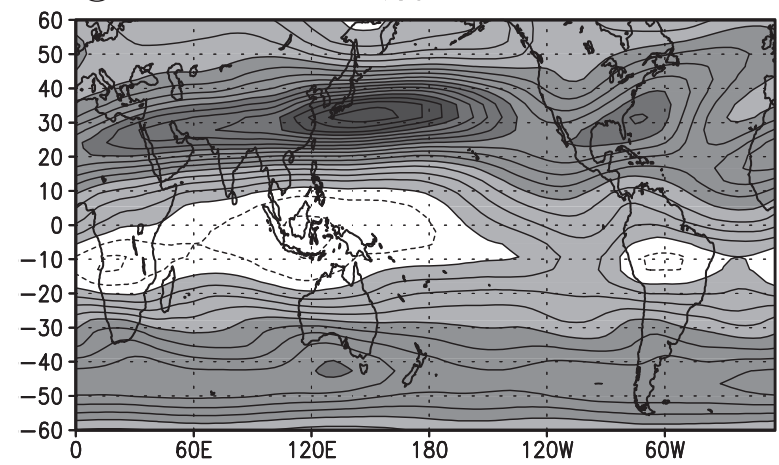

(f)

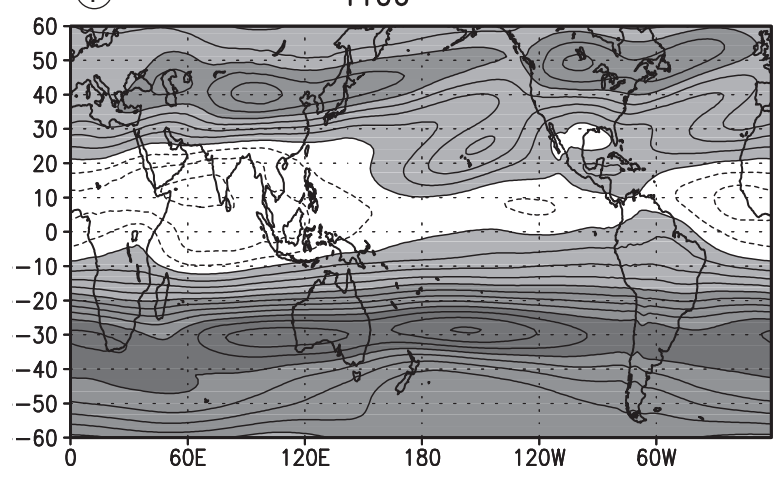

(h)

T30

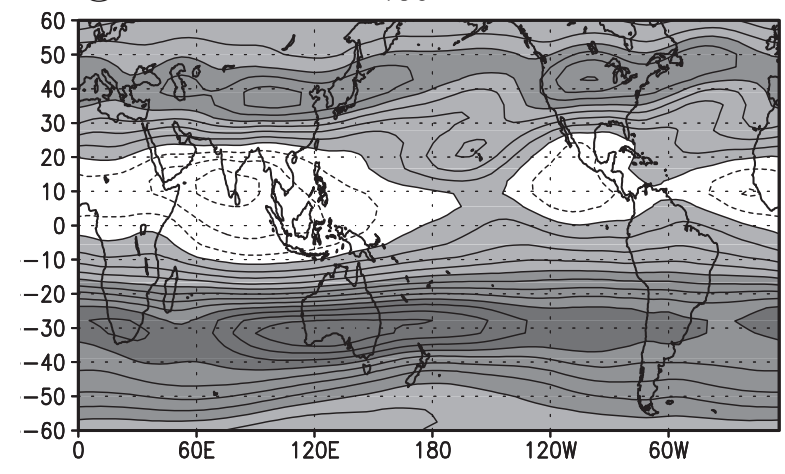

Fig. 6a-h. Same as fig. 4a-h, but for the zonal component of 200-hPa wind. Contour line interval is $5 \mathrm{~m} / \mathrm{s}$. Dashed contour lines indicate negative values; shaded areas indicate positive values; shaded contour interval is $10 \mathrm{~m} / \mathrm{s}$. 
During the JAS season (fig. 6, panels e-h), the models appear to overestimate the subtropical jet in the Southern Hemisphere, above all at the lower resolutions. In the Northern Hemisphere, the simulated patterns are similar to the re-analysis patterns, though the simulated easterlies over the Indian Ocean-Indonesian region and over the Eastern Pacific are slightly too weak. Also in contrast with the observations, the T30 and T42 models produce westerlies over the central Pacific.

\subsection{Equatorial Indo-Pacific region}

We are particularly interested in the ability of the SINTEX models to reproduce the main features of the observed climate in the IndoPacific equatorial region. Thus, it is useful to analyze in more detail the characteristics of the observed and simulated climatology in the equatorial belt.

Figure 7a-d shows the seasonal cycle of the SST along the equator (averaged between $2.5^{\circ} \mathrm{S}$ and $2.5^{\circ} \mathrm{N}$ ) for the GISST data set and for the models.

In the observations (panel a), the equatorial Pacific is characterized by warm and nearly homogeneous SST in the western part of the basin and cool SST in the eastern side. In the eastern equatorial Pacific there is a well pronounced seasonal cycle, with a maximum between March and April and a minimum around October. In the West Pacific, the SST exhibits a weak semi- (a)

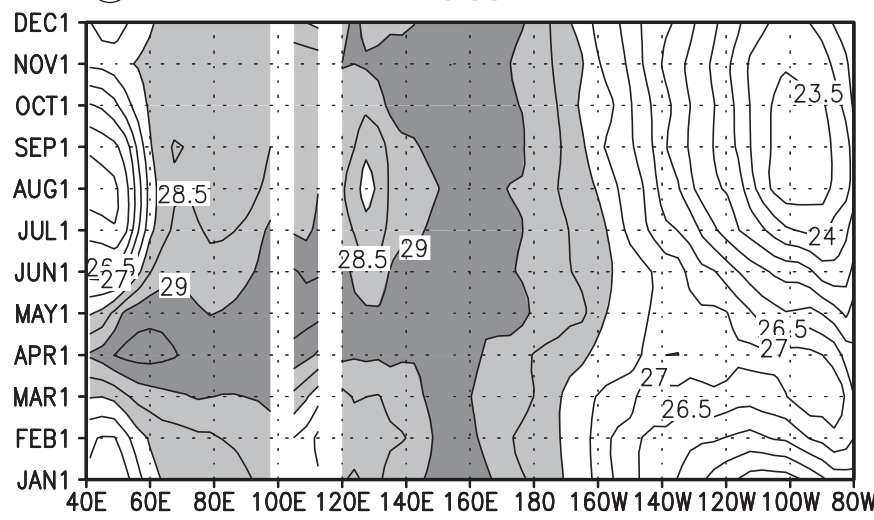

(b)

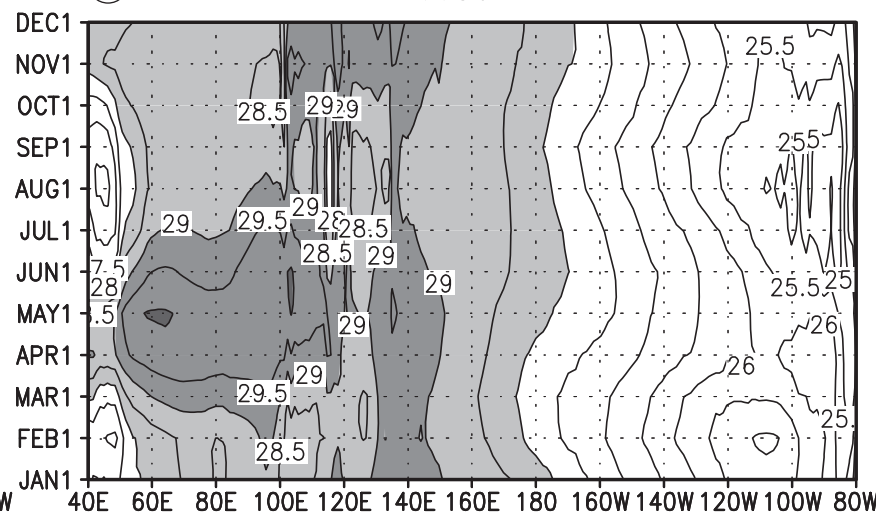

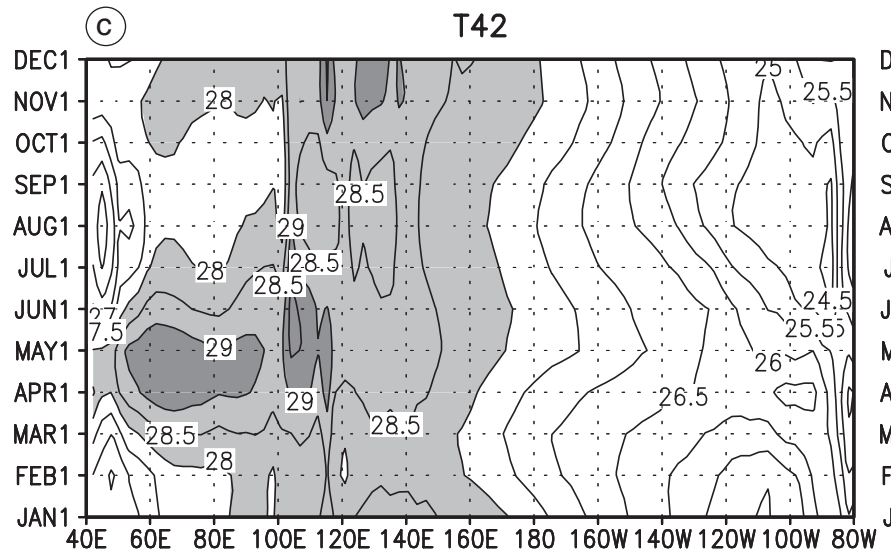
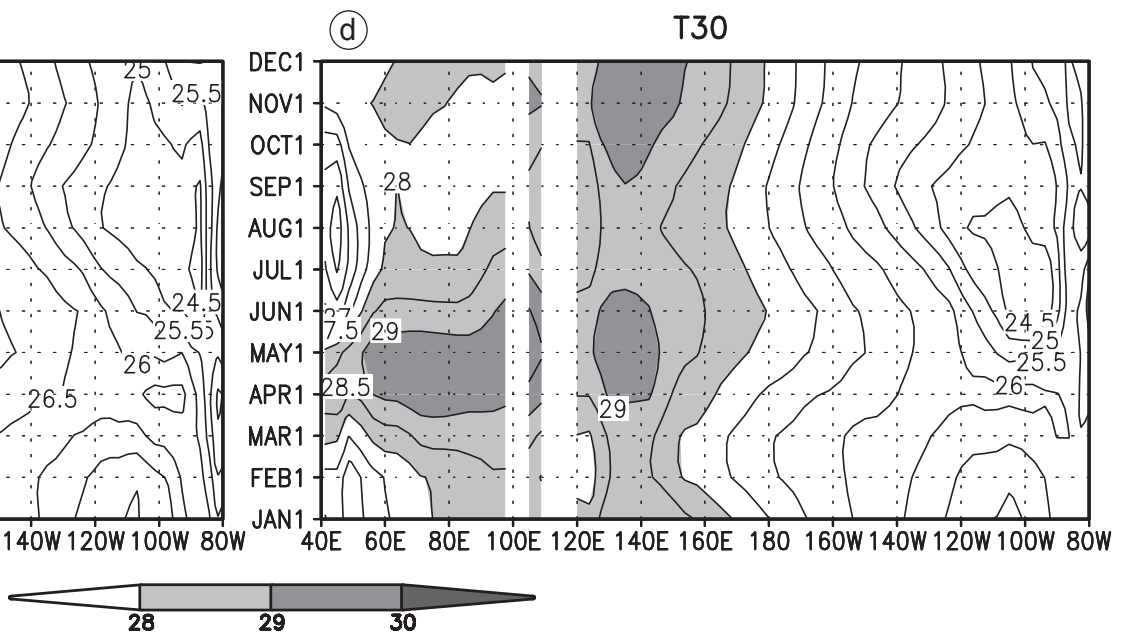

Fig. 7a-d. Seasonal cycle of the SST along the equator in the Indian Ocean and Pacific. Panel a): as derived from the GISST data set; panel b): T106 experiment; panel c): T42 experiment; panel d): T30 experiment. The vertical axis represents time, the horizontal axis longitudes. Contour line interval is $0.5^{\circ} \mathrm{C}$. Values larger than $28^{\circ} \mathrm{C}$ are shaded; the shaded contour interval is $1^{\circ} \mathrm{C}$. 
annual cycle, with minima found during northern winter and summer. The temperature difference between the two borders varies from about $2-3^{\circ} \mathrm{C}$, during the northern spring, up to more than $5^{\circ} \mathrm{C}$, during the northern autumn.

In the equatorial Indian Ocean, the zonal gradient of the observed SST appears to be opposite to the gradient found in the equatorial Pacific. In this region, in fact, the warmer SSTs are located in the central and eastern part of the basin, where they exhibit only a weak seasonal modulation. On the western border the northern summer up welling cools the SST, and a secondary minimum appears in January. During northern summer, the SST reaches its minimum and the difference between eastern and western equatorial Indian Ocean is larger than $2^{\circ} \mathrm{C}$.
The models (fig. 7, panels b-d) reproduce the basic features of the observed SST zonal distribution and seasonal cycle. However, the SST zonal gradient across both the equatorial Pacific and Indian Ocean is too small. Furthermore, the model annual cycle in the East Pacific is substantially weaker and nearly two months in advance compared to the observations. The phase lag is slightly improved in the high-resolution version. The models also tend to produce a semiannual cycle in the central Pacific, which is in contrast with the GISST case.

The seasonal cycle of the 1000-hPa equatorial (averaged between $5^{\circ} \mathrm{S}$ and $5^{\circ} \mathrm{N}$ ) zonal wind (fig. 8a-d) is basically captured by the models in the Pacific. Though, especially at low resolution (panel d) the surface easterlies are too strong (a)

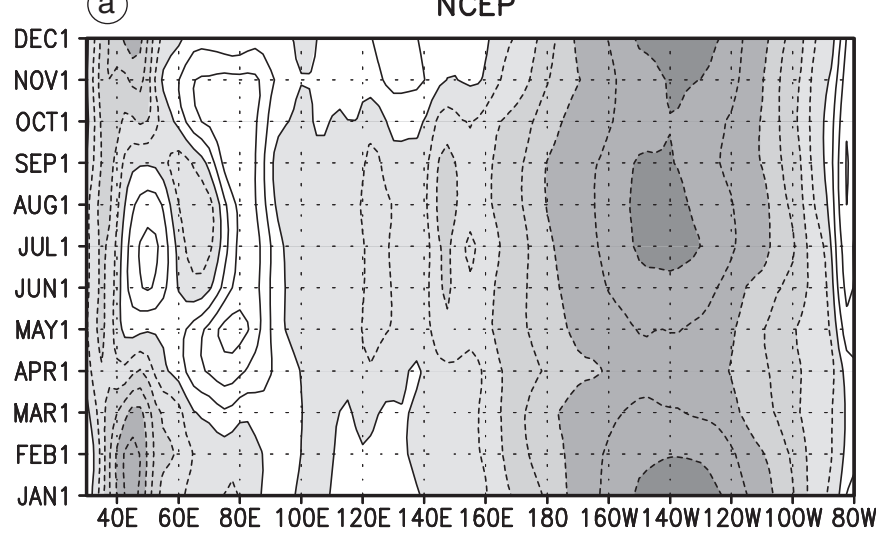

(c)

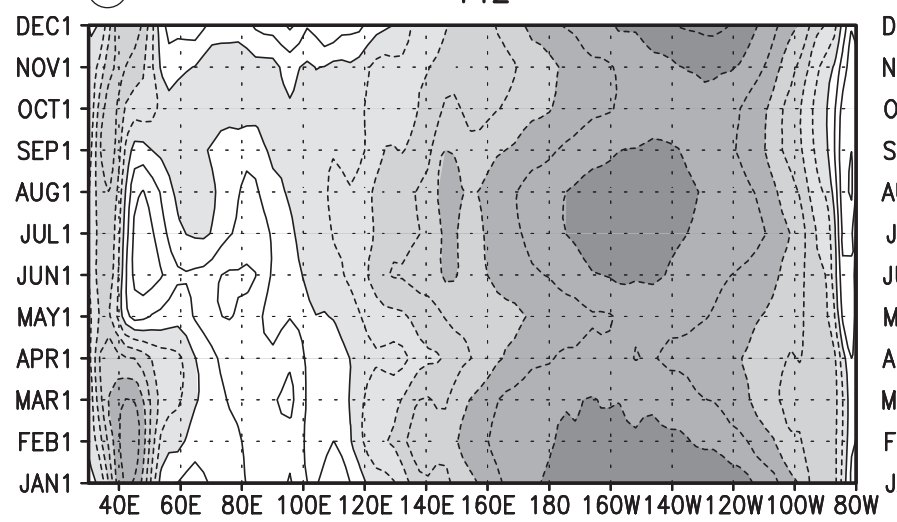

(b)

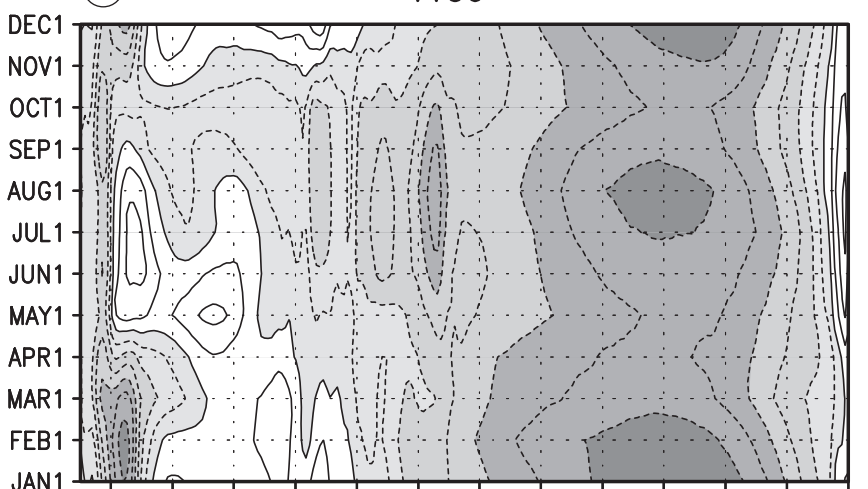

40E GOE 8OE 100E 120E 140E $160 \mathrm{E} 180$ 160W140W120W100W 80W (d)

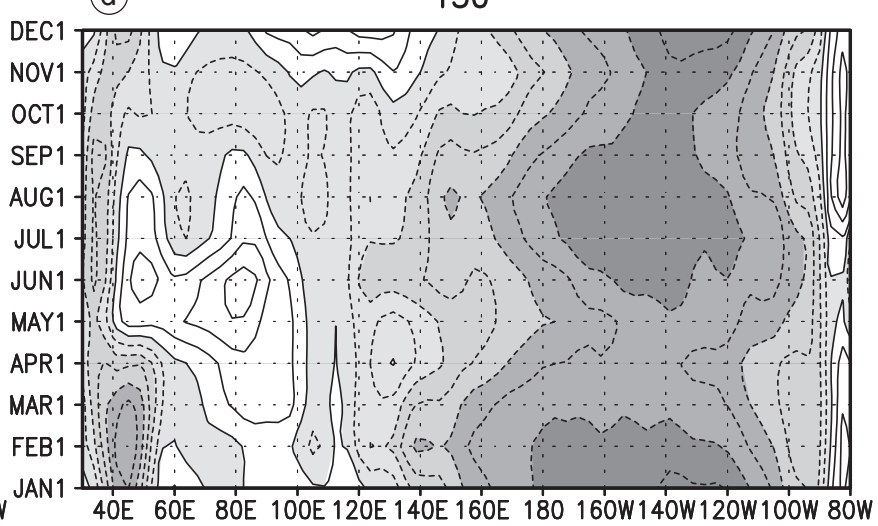

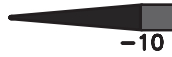
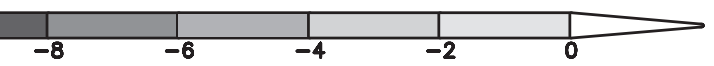

Fig. 8a-d. Seasonal cycle of the 1000 -hPa zonal wind along the equator (averaged between $5^{\circ} \mathrm{S}$ and $5^{\circ} \mathrm{N}$ ) in the Indian Ocean and Pacific. Panel a): as derived from the NCEP re-analysis; panel b): T106 experiment; panel c): T42 experiment; panel d): T30 experiment. Contour line interval is $1 \mathrm{~m} / \mathrm{s}$. Dashed contour lines and shaded areas indicate negative values; shaded contour interval is $2 \mathrm{~m} / \mathrm{s}$. 
(a)

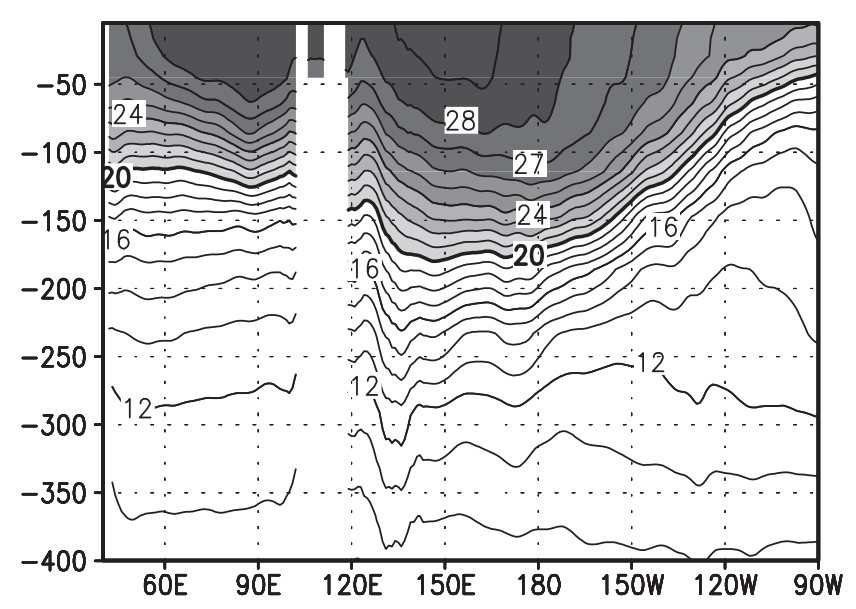

(C)

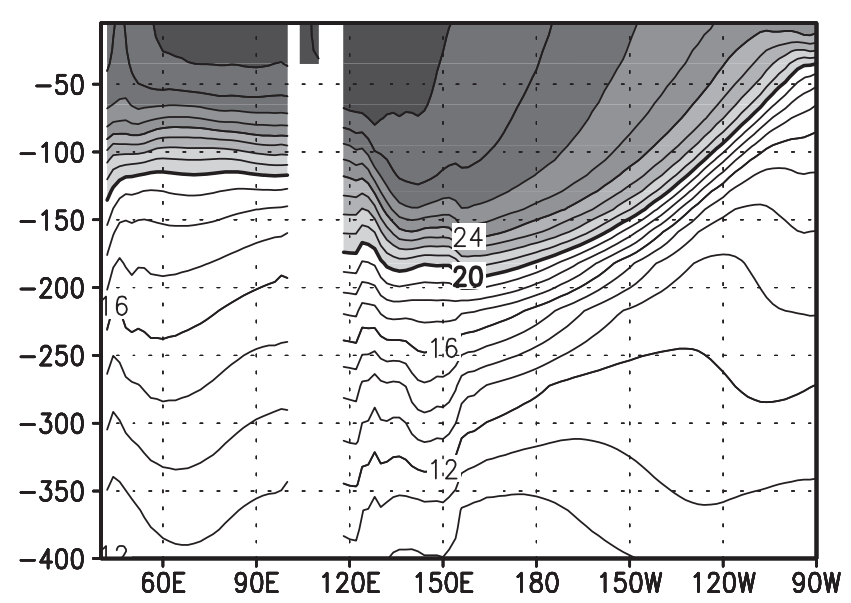

(b)

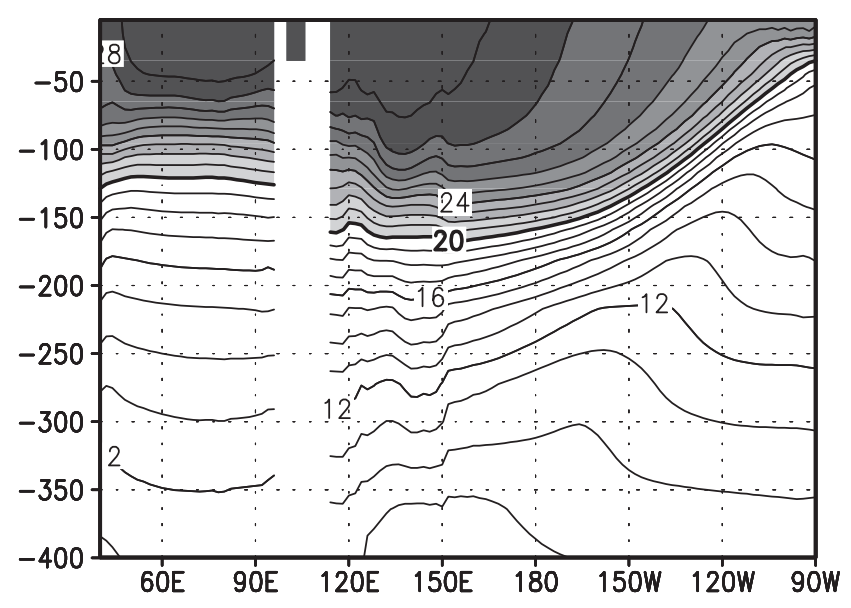

(d)

T30

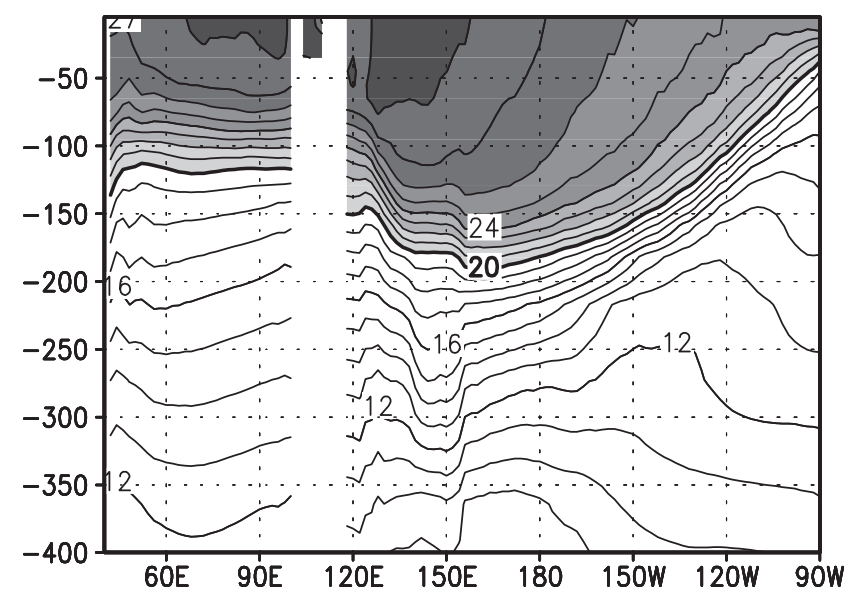

Fig. 9a-d. Vertical section of the mean temperature distribution of the upper $400 \mathrm{~m}$ along the equator in the Indian Ocean and Pacific. Panel a): as derived from the Levitus data set; panel b): T106 experiment; panel c): T42 experiment; panel d): T30 experiment. Contour line interval is $1{ }^{\circ} \mathrm{C}$. Values larger than $20^{\circ} \mathrm{C}$ are shaded; the shaded contour interval is $2^{\circ} \mathrm{C}$. The $20^{\circ} \mathrm{C}$ isotherm is bolded.

throughout the year. Furthermore, in the reanalysis (panel a), the trade winds over the Central-Eastern Pacific are substantially reduced during northern spring. In the models this trade relaxation is less pronounced, and this might explain the weaker annual modulation of the simulated SSTs.

In the equatorial Indian Ocean, the seasonal cycle of the near-surface zonal wind exhibits patterns with a more complicated structure. The models appear to be successful in reproducing some of them. For example, the transition from dominant surface easterlies to surface westerlies, observed in the western part of the basin, is reasonably well simulated. This change in the low-level flow occurs between northern winter and northern summer, and is related to the Indian monsoon phase.

In the central equatorial Indian Ocean, on the other hand, the zonal wind seasonal cycle appears to be characterized by an alternation of easterlies and westerlies, which is only partially reproduced by the models.

In fig. 9a-d, a vertical section of the mean temperature in the equatorial Indian and Pacific Ocean is shown. The general features of the 
equatorial temperature structure, like the sharpness and the slope of the thermocline, are reasonably well represented by the models. However, a comparison with the reference case (panel a) indicates that in the low-resolution models (panels c, d) the Western Pacific warm pool is eroded, and the thermocline is too deep. In the T106 case (panel b), consistently with the improved near-surface zonal wind in the equatorial Pacific (fig. 4a-h and 8a-d), both the warm pool extension and the thermocline depth are closer to the observations.

\section{Interannual variability in the tropical Indo-Pacific region}

Our main goal in developing the SINTEX coupled GCMs was to investigate the climate variability and the possible interactions between phenomena characterized by different time scales (e.g., interannual and intraseasonal variability). As a first step, it is of interest to give an assessment of the ability of the models to reproduce the main features of the observed variability. In particular, in this paper, we focus our attention on the interannual variability in the Indo-Pacific tropical region.

A first assessment of the variability in the tropical Pacific can be inferred by the standard deviation patterns of the SST. Figure 10a-d shows the SST standard deviation, in the tropical belt, computed using deviations with respect to the seasonal cycle. In the Tropics, the observed SST variance (panel a) is dominated by the variability located across the equatorial Central-Eastern Pacific. In this region the major contribution to the SST variability comes from the El Niño
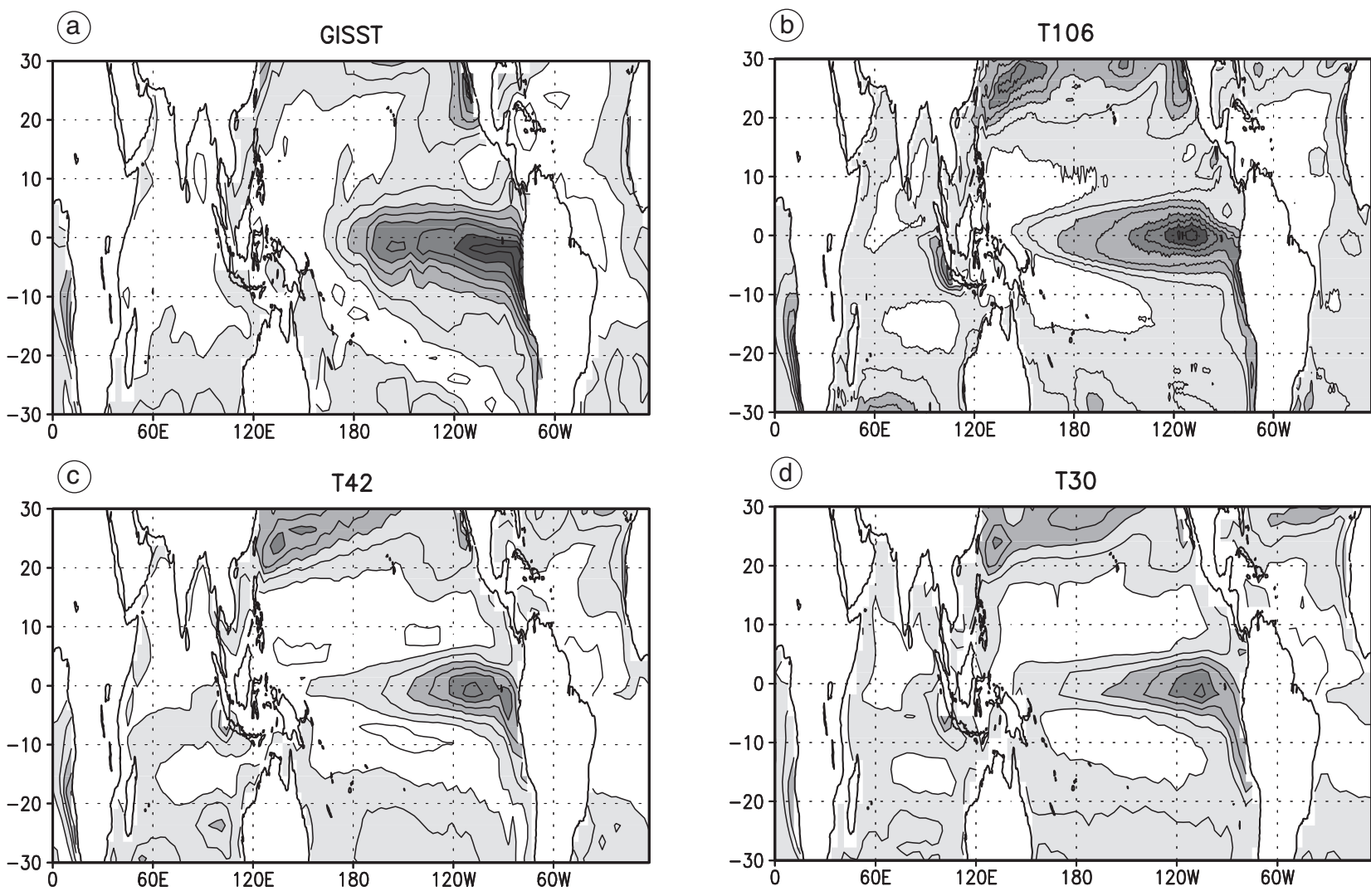

(d)

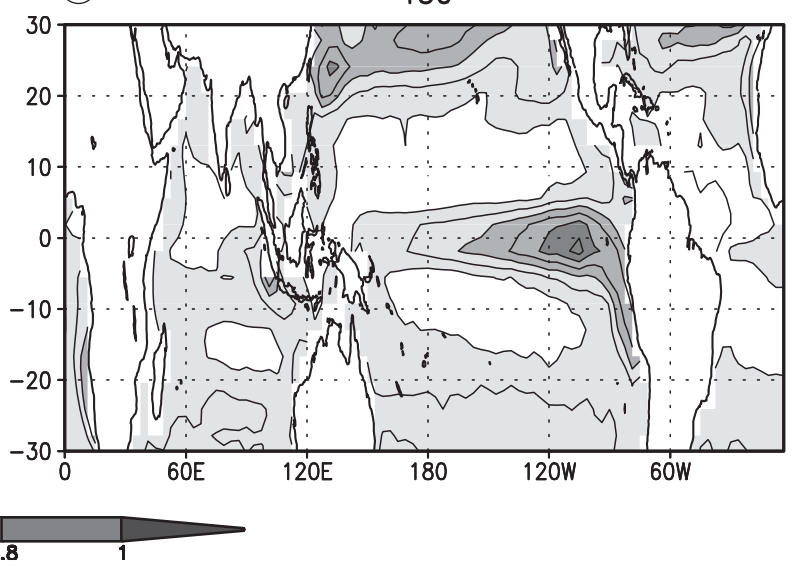

Fig. 10a-d. Standard deviation of the SST field in the Tropics. Panel a): as derived from the GISST data set; panel b): T106 experiment; panel c): T42 experiment; panel d): T30 experiment. Contour line interval is $0.1^{\circ} \mathrm{C}$. Values larger than $0.4^{\circ} \mathrm{C}$ are shaded; the shaded contour interval is $0.2^{\circ} \mathrm{C}$. 
activity. The models (panels b-d) seem to reproduce the basic structure of the observed variance patterns, though the simulated variability appears to be weaker, especially in the lower resolution versions. It is worthwhile to notice that the meridional extension of the SST variability pattern is improved with the T106 model version.

In the Indian Ocean, on the other hand, the simulated SST variability is stronger than in the GISST data set, particularly in the eastern part of the basin. Also in the north subtropical Pacific, especially at the western boundary, the simulated variance appears to be stronger than observed.

\subsection{The ENSO variability}

The El Niño/Southern Oscillation (ENSO) is the strongest regular tropical signal on interannual time scale (for a comprehensive review see Philander, 1990, and the J. Geophys. Res. special issue on the TOGA decade, vol. 103, 1998). The quality of the ENSO-like variability simulated by a CGCM is an important component of the assessment of the model.

A commonly used index for ENSO studies is the time series of the SST anomaly averaged over the so called NINOO- 3 region $\left(150^{\circ} \mathrm{W}-90^{\circ} \mathrm{W}, 5^{\circ} \mathrm{S}\right.$ $\left.5^{\circ} \mathrm{N}\right)$. Such a time series is presented in fig. $11 \mathrm{a}-\mathrm{c}$,

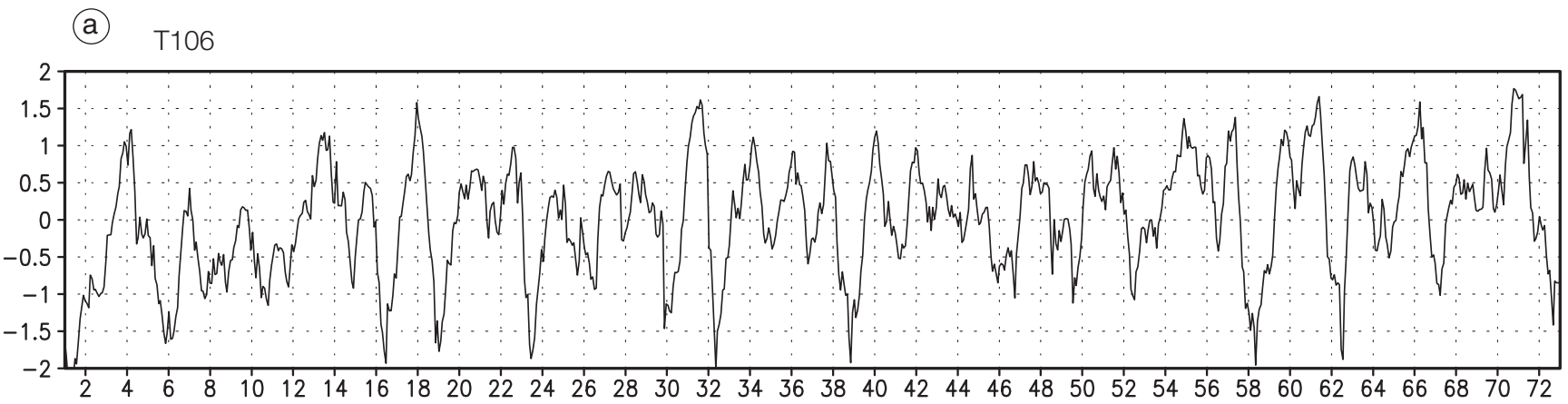

(b) T42

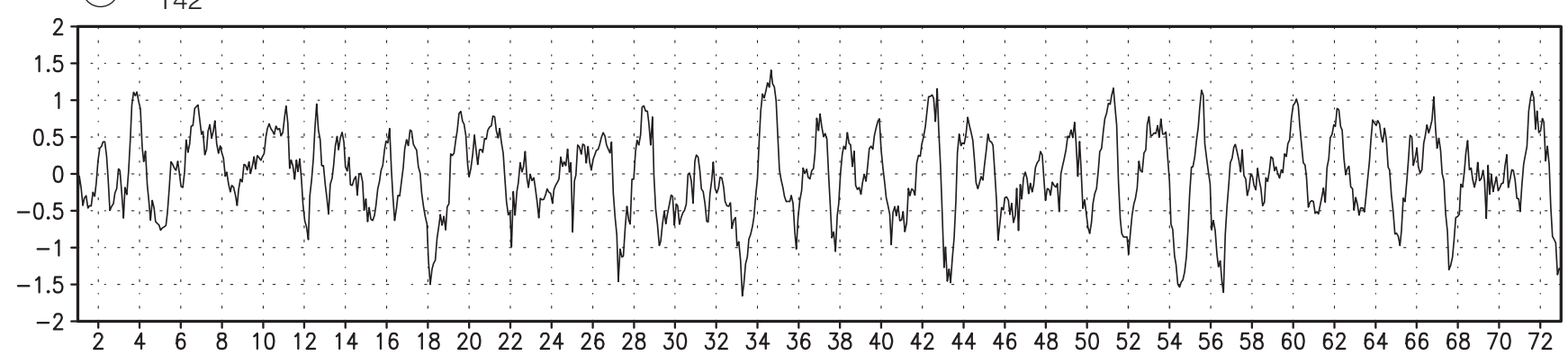

(C) T30

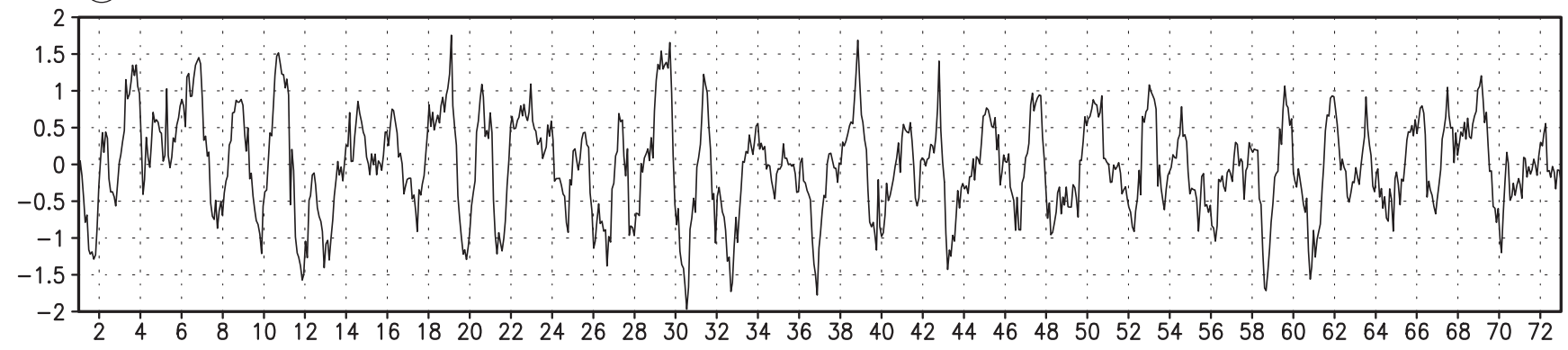

Fig. 11a-c. Time series of the SST anomaly averaged over the NINO-3 region $\left(150^{\circ} \mathrm{W}-90^{\circ} \mathrm{W}, 5^{\circ} \mathrm{S}-5^{\circ} \mathrm{N}\right)$. The anomalies are computed with respect to the mean annual cycle. Panel a): T106 experiment; panel b): T42 experiment; panel c): T30 experiment. 
where 73 years of the model integrations are shown. For each model, the monthly anomalies have been computed as deviations from the mean annual cycle. In the T30 and T42 cases, the mean annual cycle has been computed using the entire 200 -year data set. The results shown in fig. 11a-c for these models do not differ much from the rest of the integration period (200 years).

In the T106 case, the time series drifts of about $0.5 \mathrm{C}$ over the entire period, whereas for the T30 and T42 cases, the drift is practically absent. Overall, the amplitude of the simulated NIÑO-3 SST anomaly (NIÑO-3 SSTA) is comparable to the observed one, though in the T42 model it is slightly weaker.

An important feature of El Niño is its seasonal character. The largest SST anomaly in the eastern equatorial Pacific are generally observed during northern winter (Philander, 1990). Figure 12 shows the composite of the SST anomaly in the NIÑO-3 region for the observations and model simulations. The composites have been computed by averaging the monthly anomalies corresponding to ENSO events for which the NIÑO-3 index is larger than 1.5 standard deviation. Thus, the sequence of the composites shows the evolution of the «mean» intense ENSO episode.

The results shown in fig. 12 indicate that the models, at all resolutions, reproduce quite well the seasonal occurrence of the ENSO episodes. In agreement with the observations, the simulated ENSO peaks during northern winter. Also consistent with the observations, the year preceding the peak of the event (year 0) is characterized by weak negative SST anomalies (weak La Niña conditions).

After the termination of the event, which occurs between northern spring and summer of the «year after» (year 2 in fig. 12), the anomalies become negative again. This transition from warm (El Niño) to cold (La Niña) conditions appears to be more pronounced in the model simulations, especially in the low-resolution version T30.

The ENSO variability exhibits also a lowfrequency modulation of its activity (Latif et al., 1997). Following the procedure used in Achuta Rao et al. (2001), we have computed the lowfrequency changes in the NIÑO-3 SSTA standard deviation, and fig. 13 shows it for the different

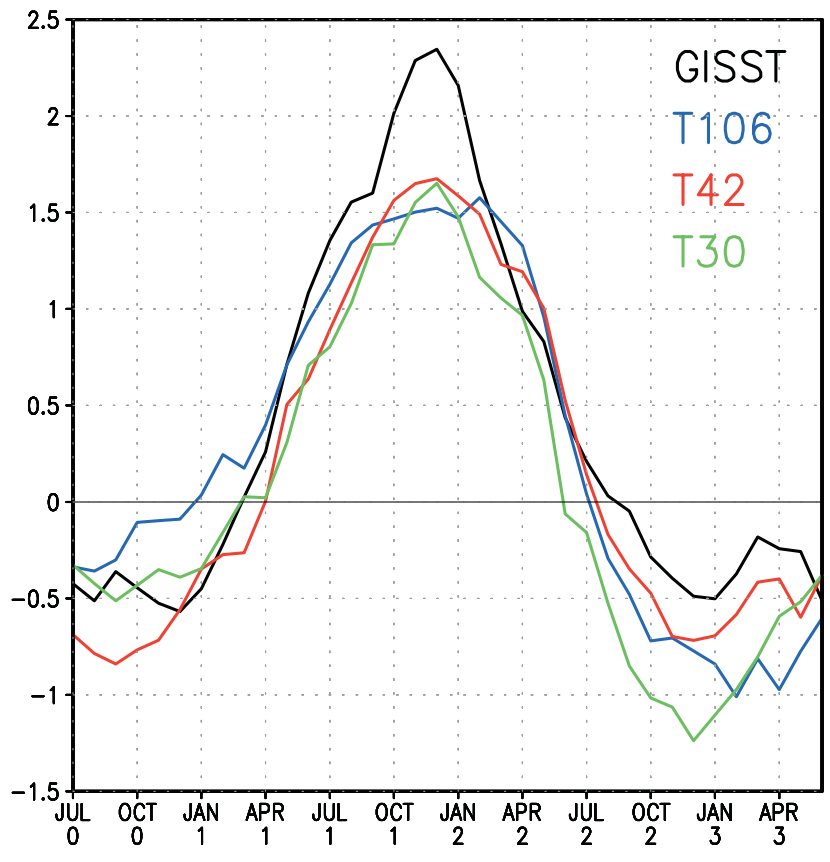

Fig. 12. Composite of the NIÑO-3 SST anomaly. The composite have been computed by averaging the monthly anomalies corresponding to ENSO events for which the NIÑO-3 index is larger than 1.5 standard deviation. In the GISST case (black curve) 8 episodes have been considered (year 1957-58, 1965-66, 1972$73,1982-83,1986-87,1991-92$ and 1997-98). For the T106 model (blue line), 12 events have been used to yield the composite; whereas, for the T42 (red curve) and the T30 (green curve) 21 episodes have been used. Vertical axis: ${ }^{\circ} \mathrm{C}$.

model resolutions. The curves indicate that the models produce a substantial temporal modulation of the ENSO variability, and the magnitude of these variations is close to the results found from the observations (Achuta Rao et al., 2001).

Another important feature of the ENSO variability is the frequency of the oscillation. Figure 14 shows the results of a spectral analysis of the NIÑO-3 SSTA time series. For the observations (black curve) a dominant broad peak is found at about 4 years; whereas the model, at all the resolutions, has the larger peaks at shorter periods. The spectra obtained from the model runs also exhibit important differences. The T30 case (fig. 14, green curve) has a single peak centered at about 24 months, indicating a predominant quasi-biennial behavior of the simulated ENSO (see also Guilyardi et al., 2003). 


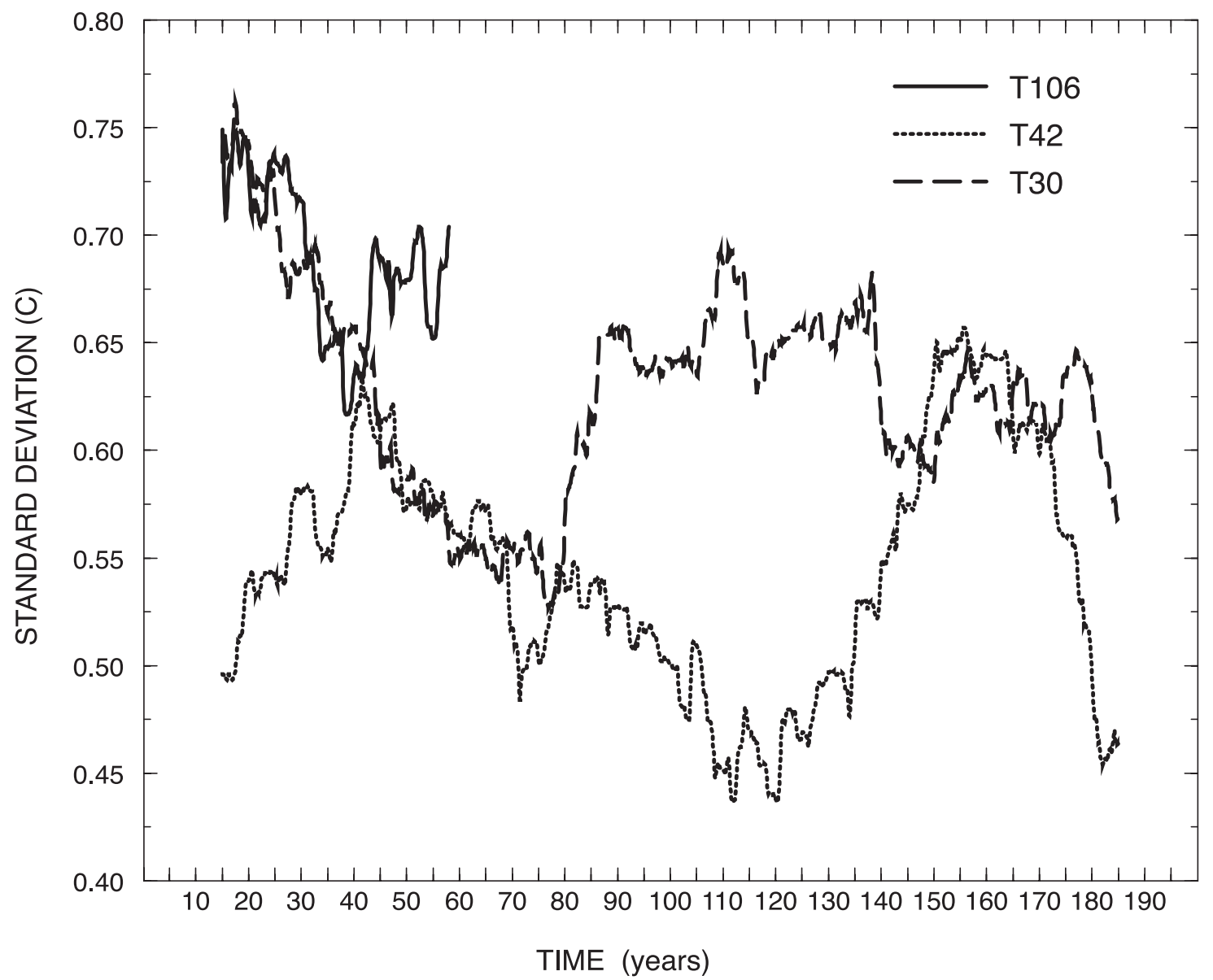

Fig. 13. Standard deviation over moving 15-year windows for the NIÑO-3 SSTA. Solid line curve: T106 experiment; dotted line curve: T42 experiment; dashed line curve: T30 experiment.

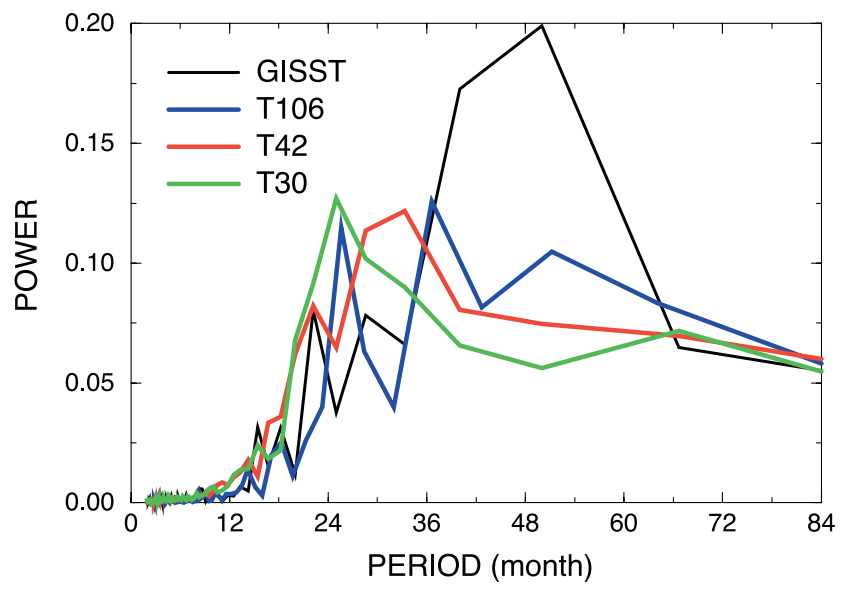

Fig. 14. NIÑO-3 SSTA spectrum. Black curve as obtained from the GISST data set; blue curve: T106 experiment; red curve: T42 experiment; green curve: T30 experiment. Before to compute the spectra the NIÑO-3 SSTA time series were normalized by their respective standard deviations.
In the T42 model, the dominant peak appears to be shifted to lower frequency, being now centered around a period longer than 30 months. Therefore, in the T42 case, the ENSO seems to be slightly weaker but closer to the observations, at least in terms of periodicity. In the T106 experiment, finally, the oscillation appears to be characterized by two dominant frequencies: a quasi-biennial and a 3-year period. These results suggest that the horizontal resolution of the atmospheric component of the coupled model might be important for the simulation of the ENSO-like variability.

Another suggestion of a possible impact of the atmospheric model resolution on the simulated ENSO variability is provided by the results shown in figs. 15a-d and 16a-d. Figure 15a-d shows the maps of correlation of the NIÑO-3 
(a)

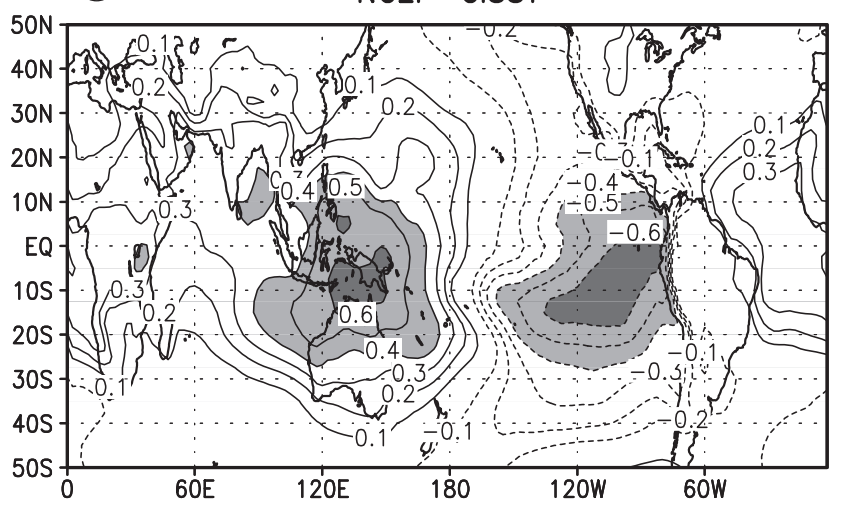

(C)

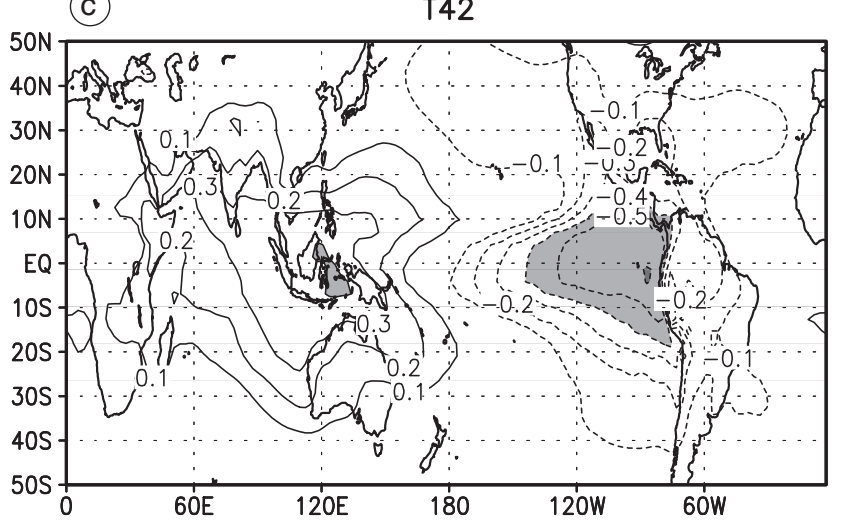

(b)

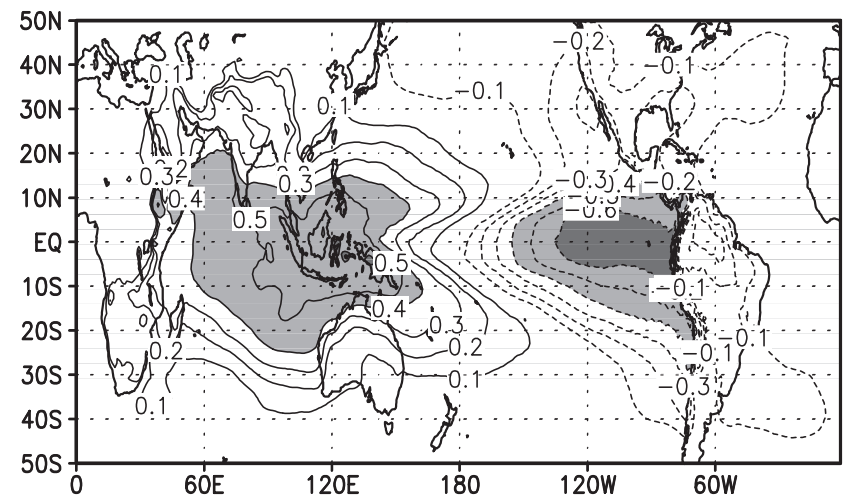

(d)

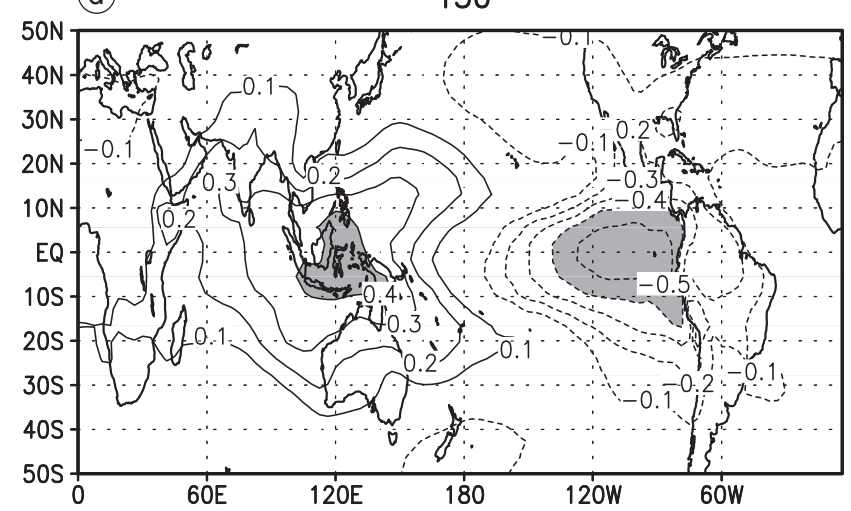

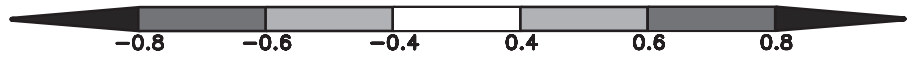

Fig. 15a-d. Maps of correlation of the NIÑO-3 SSTA time series with the global Sea-Level Pressure (SLP) anomaly. Panel a): NCEP-GISST case; panel b): T106 experiment; panel c): T42 experiment; panel d): T30 experiment. Contour line interval is 0.1 ; dashed contour lines indicate negative values; shaded areas indicate values larger than $|0.4|$; the shaded contour interval is 0.2 .

SSTA time series with the global Sea-Level Pressure (SLP) anomaly. In the NCEP-GISST case (fig. 15, panel a), the correlation map reproduces the patterns of SLP teleconnections associated with ENSO (Trenberth et al., 1998). The correlation has two centres of high values, with opposite sign. One is located over the tropical Eastern Indian Ocean-Western Pacific and the other over the tropical Central-Eastern Pacific. The fluctuations of the SLP over these regions identifies the Southern Oscillation (Walker and Bliss, 1932; Philander, 1990). When the SST increases over the NIÑO-3 region, negative SLP anomalies cover the tropical and sub-tropical central-eastern Pacific. In contrast, the SLP increases over the Western Pacific and Indian Ocean.

All model experiments (fig. 15, panels b-d), and especially the T106 case, reproduce, in its gross aspects, the features of the observed teleconnections, though the simulated SLP signal appears to be more confined to the equatorial region. In contrast with the reference case, the model negative correlation patterns tend to penetrate the West Pacific along the equator. This discrepancy is probably associated with the model tendency to produce a too strong Walkertype circulation and a marked equatorial cold tongue. Finally, the models appear to underestimate the SLP teleconnections between the 
(a)

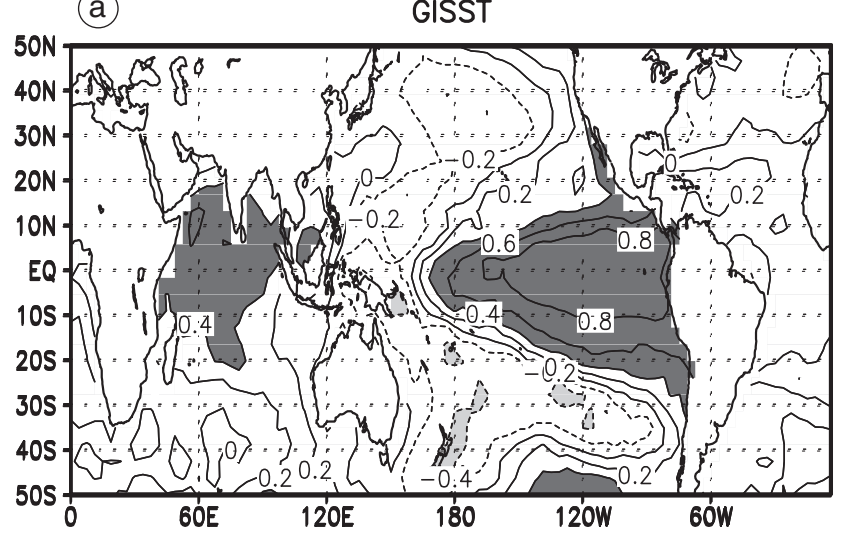

(C)

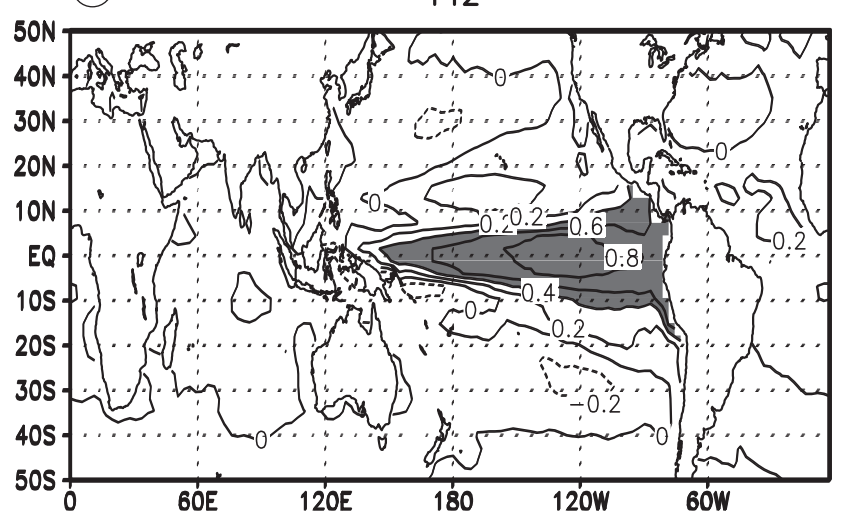

(b)

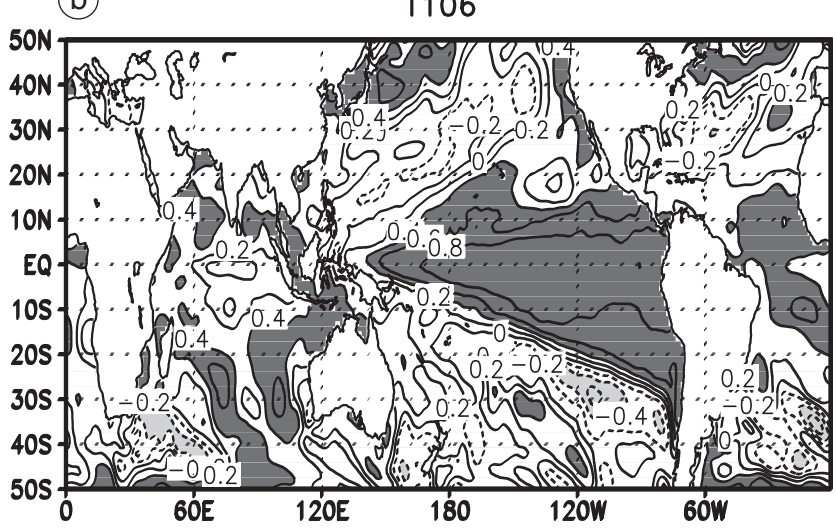

(d)

T30

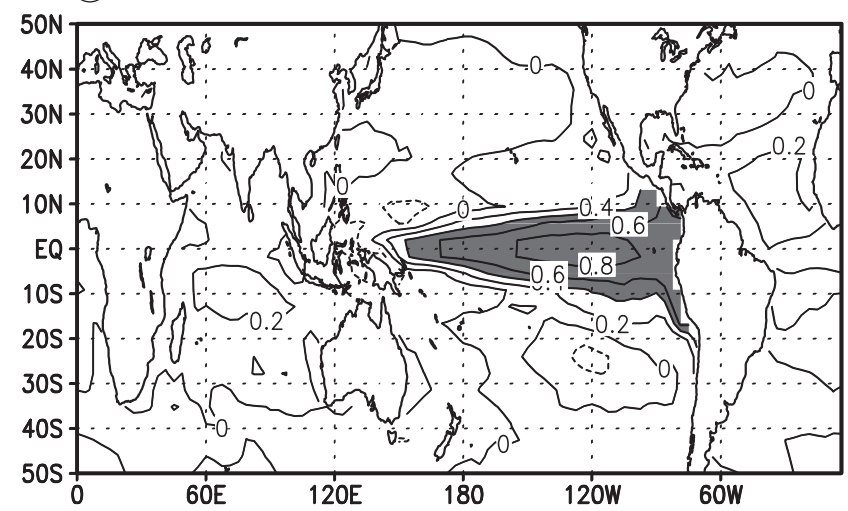

Fig. 16a-d. Maps of correlation of the NIÑO-3 SSTA with the global SST anomaly. Panel a): GISST case; panel b): T106 experiment; panel c): T42 experiment; panel d): T30 experiment. Contour line interval is 0.2; dashed contour lines indicate negative values; shaded areas indicate values larger than |0.4|; the shaded contour interval is 0.2 .

tropical Indo-Pacific region and the tropical Atlantic and Africa.

Figure 16a-d shows the correlation patterns of the NIÑO-3 SSTA time series with the global SSTA. The GISST result (fig. 16, panel a) shows the well-known connection between the fluctuations of the SST in the NIÑO-3 region and the variations of the SST over the entire tropical and sub-tropical Indo-Pacific region (e.g., Philander, 1990; Trenberth et al., 1998). The models (fig. 16, panels b-d) reproduce the correlation patterns over the tropical CentralEastern Pacific. However, in the lower resolution versions, the positive correlation pattern appears to be markedly confined to the equatorial Pacific region. In the T106 version, in contrast, the structure of the positive correlation pattern in the tropical Pacific is much closer to the reference case.

The observed link between the SST fluctuation over the tropical Indian Ocean and ENSO variability seems to be at least partially captured with the T106 model, whereas the horseshoe pattern of negative correlation found in the western and extra-tropical Pacific for the observations is only poorly reproduced by the models.

\subsection{Tropical Indian Ocean}

Recent observational studies have shown that the tropical Indian Ocean exhibits anomalous conditions at interannual time scales, which, apparently, seem to be independent from the 
ENSO cycle (Saji et al., 1999; Webster et al., 1999). In particular, Saji et al. (1999) (hereafter S99) have identified a mode of variability characterized by a zonal bipolar structure, the so-called Indian Ocean Dipole Mode (IODM). The extremes of this dipole are located over the eastern and western equatorial Indian Ocean. In its positive phase, the dipole is characterized by warm SST anomalies in the Western Indian Ocean (WIO) and cold anomalies in the Eastern Indian Ocean (EIO).

The SST anomalies are coherently related with surface winds and precipitation anomalies, and the observational results seem to indicate that this variability is the product of a coupled oceanatmosphere phenomenon (Webster et al., 1999). The mode exhibits also a pronounced seasonality, with the largest anomalies observed during northern autumn.

Our objective here is to show how the SINTEX model is able to reproduce the basic observed features of the IODM.

In order to identity the dominant modes of SST variability in the tropical Indian Ocean, an Empirical Orthogonal Function (EOF) analysis has been applied to the SST anomalies in this region, both for the observations and model simulations. The results obtained from the different versions of the model are in their gross general features quite similar. Therefore, for the sake of brevity, in this paper we limit our discussion to the T42 case.

The results obtained for the GISST case indicate that the variability of anomalous Indian Ocean SSTs is dominated by a basin-wide mode (EOF1, not shown), which explains about 30\% of the total SST variance. The high correlation between the time series of the EOF1 principal component and NIÑO-3 SSTA $(r=0.7$ with a time lag of 5 months with the NIÑO-3 leading) suggests that this mode of variability is strongly linked to the ENSO activity. Similar results were found by S99 and Venzke et al. (2000).

The second mode of variability (EOF2, not shown) explains about $12 \%$ of the total variance, and it is characterized by a zonal bipolar structure. The extremes of this dipole are located over the western and south-eastern part of the Indian Ocean.

The EOF analysis results obtained from the simulated SST anomalies in the tropical Indian
Ocean are very similar to the observational results. The variability of the modelled SST is dominated by a basin-scale mode (EOF1, not shown), which explains about $20 \%$ of the total variance. The time series of the EOF1 principal component (not shown) is well correlated $(r=0.6)$ with the NIÑO-3 SST anomaly time series with a time lag of about 5 months, with the NIÑO-3 leading. In the model the variance explained by EOF1 (20\%) is smaller than in the observations $(30 \%)$. Since we think that this mode of variability is strongly related to the ENSO activity, the smaller simulated variance might be due to the substantially weaker ENSO signal found in the model simulations, and especially in the T42 case (see Section 5.1).

The second EOF mode (not shown) has a zonal bipolar structure with a reversal in sign of the SST anomalies across the basin, and with the extremes located in the WIO and in the EIO. This second mode explains, in all cases, about $10 \%$ of the total variance.

These results indicate, in very good agreement with the observations, that the model has in the Indian Ocean two dominant modes of variability: the first mode is basin wide and is related to the ENSO variability; the second mode represents the fluctuation of the zonal distribution of the SST.

Following S99, we identify the second (dipole) mode with a simple index defined as the difference in SST anomaly between the WIO $\left(50^{\circ} \mathrm{E}-70^{\circ} \mathrm{E} ; 10^{\circ} \mathrm{S}-10^{\circ} \mathrm{N}\right)$ and the southern EIO $\left(90^{\circ} \mathrm{E}-110^{\circ} \mathrm{E} ; 10^{\circ} \mathrm{S}\right.$-Equator). This index, hereafter Dipole Mode Index (DMI), is well correlated with the principal component time series of the second EOF mode, and it can be considered representative of the fluctuations in the zonal distribution of the SST across the tropical Indian Ocean.

Figure $17 \mathrm{a}-\mathrm{c}$ shows a 50-year DMI time series (solid line), for the three model runs. The results shown in this picture for the T30 and T42 models do not differ much from the rest of the integration period (200 years). For all model resolutions and consistently with S99, the DMI generally tends to have larger amplitudes in its positive phase. This indicates that a strong variability is produced by anomalous conditions in the tropical Indian Ocean characterized by cold 


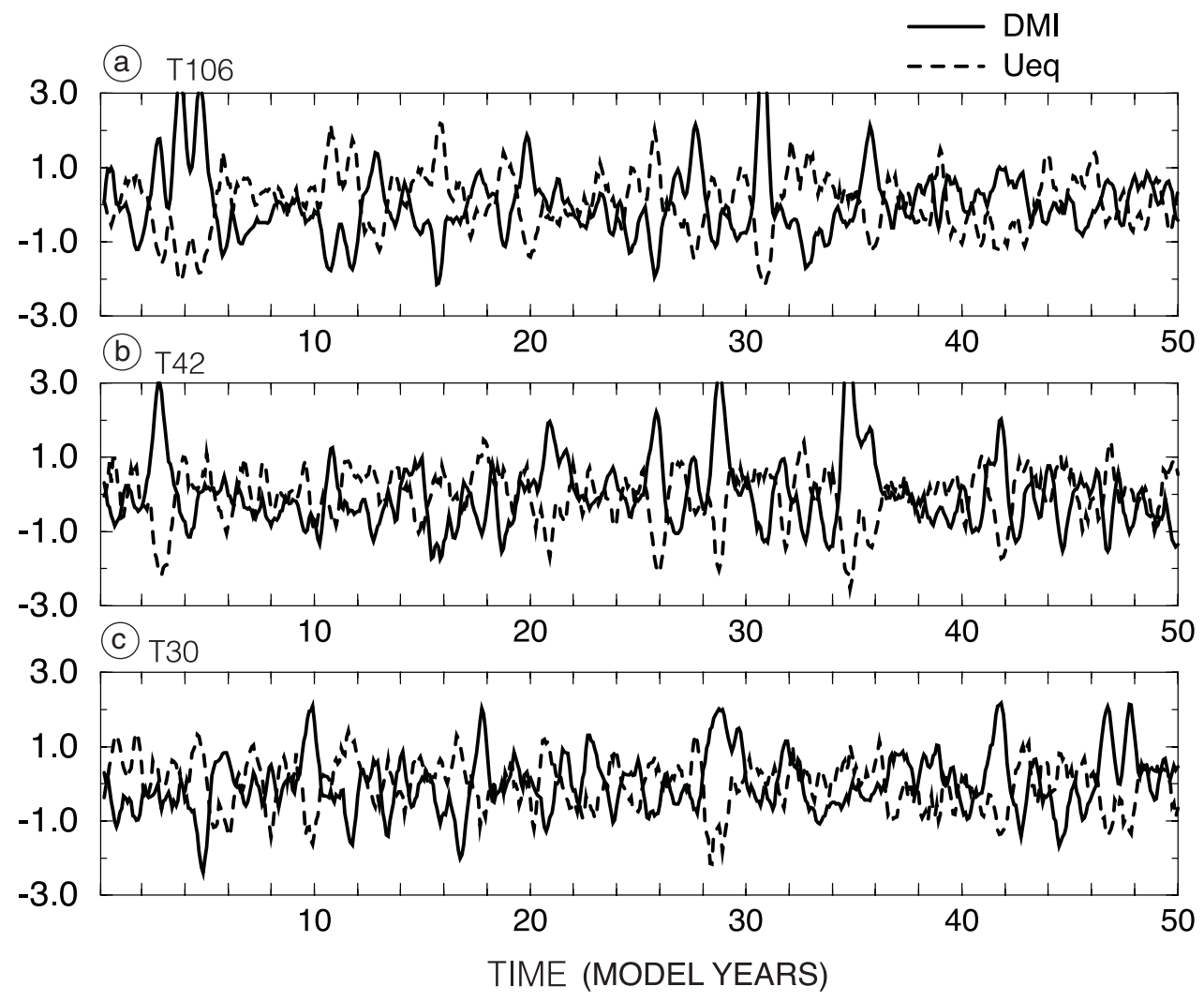

Fig. 17a-c. Solid line curve, time series of the Dipole Mode Index (DMI) defined as the SST anomaly between the WIO $\left(50^{\circ} \mathrm{E}-70^{\circ} \mathrm{E} ; 10^{\circ} \mathrm{S}-10^{\circ} \mathrm{N}\right)$ and the southern $\mathrm{EIO}\left(90^{\circ} \mathrm{E}-110^{\circ} \mathrm{E} ; 10^{\circ} \mathrm{S}\right.$-Equator $)$. Dashed line curve, time series of the zonal wind anomaly averaged over the region: $70^{\circ} \mathrm{E}-90^{\circ} \mathrm{E} ; 5^{\circ} \mathrm{S}-5^{\circ} \mathrm{N}$. Panel a): $\mathrm{T} 106$ experiment; panel b): T42 experiment; panel c): T30 experiment.

SST in the south-eastern part and warm SST in the western border.

Together with the DMI, the time series of the equatorial zonal wind anomaly (averaged over the region: $70^{\circ} \mathrm{E}-90^{\circ} \mathrm{E} ; 5^{\circ} \mathrm{S}-5^{\circ} \mathrm{N}$ ) are also plotted (dashed curve). These plots, in agreement with the observations (S99), indicate that the changes of the simulated SST zonal distribution and the fluctuation of the equatorial zonal wind are strongly correlated.

An important feature of the observed dipole mode is its pronounced seasonality, with the anomalies that clearly peak during the northern autumn (S99). Figure 18 shows the seasonality of the DMI in its positive phase (DMI $>0)$, as obtained from the GISST data set (solid line curve) and from the model experiments. The seasonal character of the DMI is generally captured by the models, though in all of them the DMI peak tend to occur slightly in advance compared with the observations.

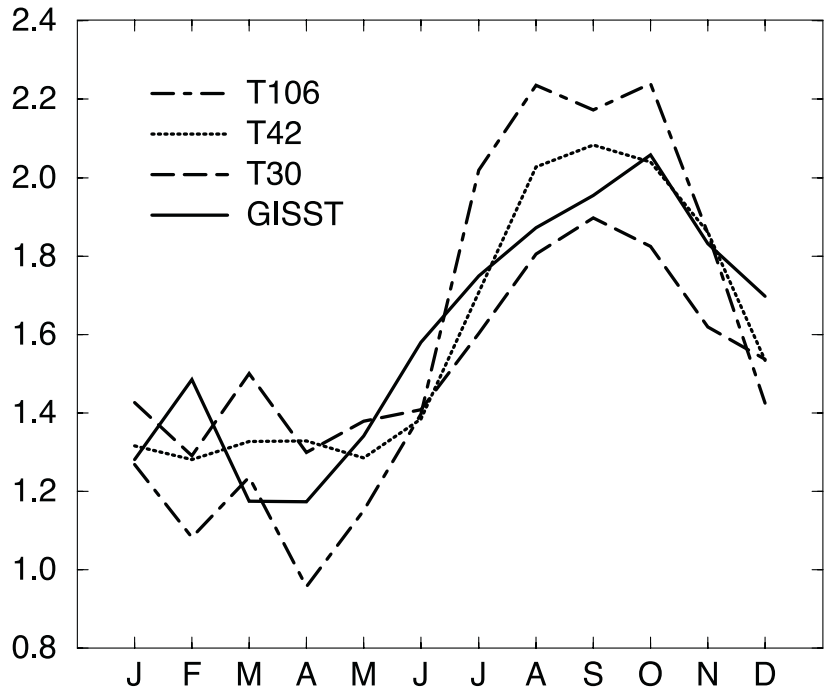

Fig. 18. Seasonal modulation of the DMI, computed as the monthly means of the amplitude of the DMI. Solid line curve: GISST data set; dot-dashed curve line: T106 experiment; dotted line curve: T42 experiment; dashed line curve: T30 experiment. 
(a)

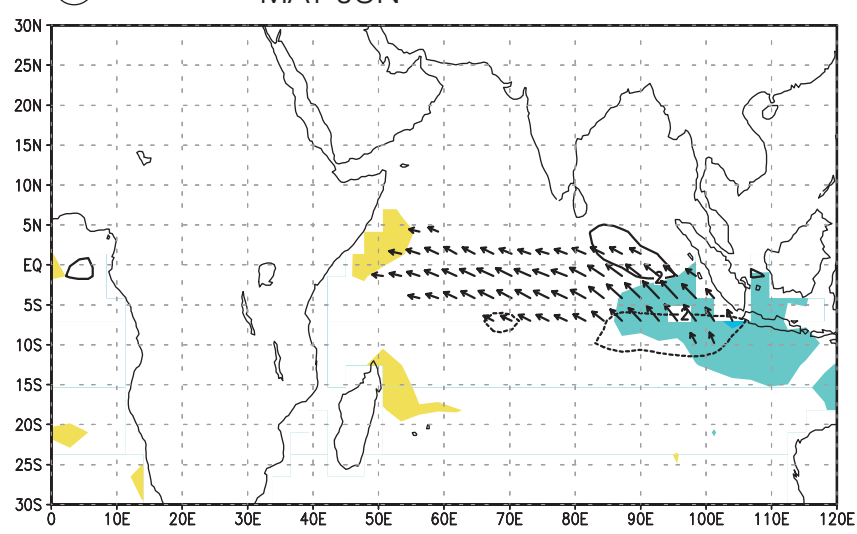

(b)

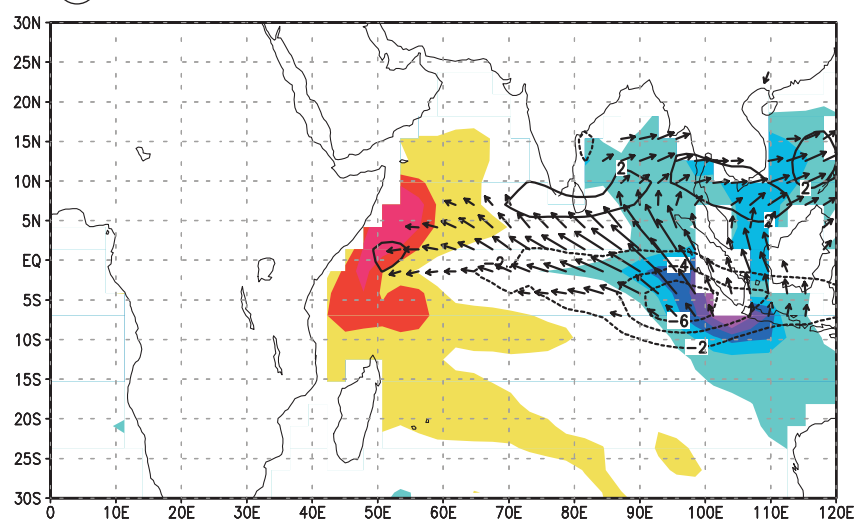

(C)
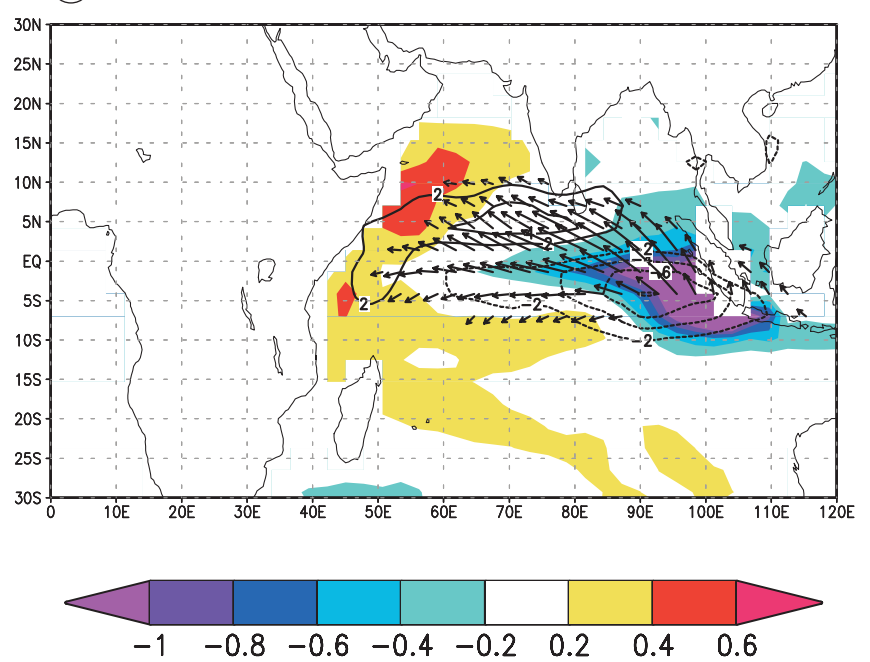

Additional insight into the characteristics of the IODM variability can be obtained by calculating composite analyses to yield the patterns of precipitation and near-surface wind anomalies (d)

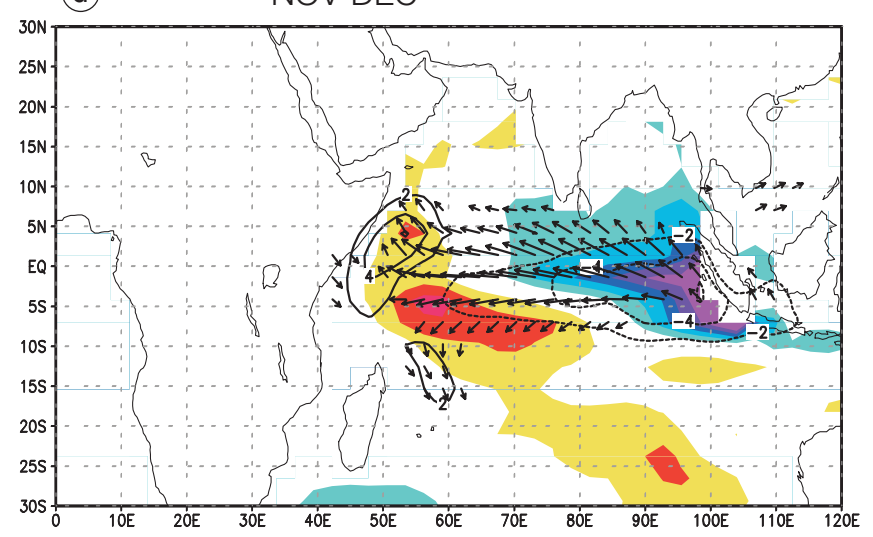

(e) JAN-FEB

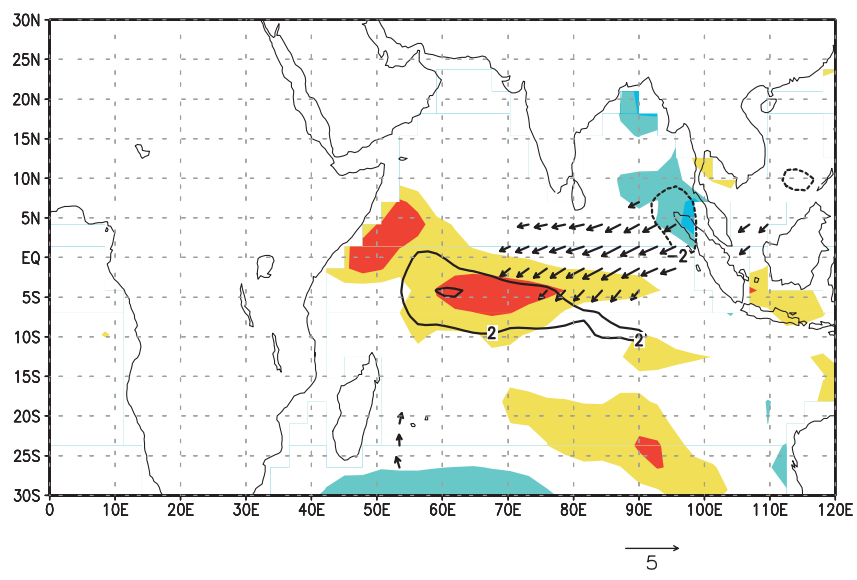

Fig. 19a-e. Composite patterns of the SST anomaly (shaded), 1000-hPa wind anomaly (arrows) and precipitation anomaly (contour) obtained for the T42 model. The composite have been computed using the DMI as an index of the dipole mode. Panel a): MayJune composite; panel b): July-August composite; panel c): September-October composite; panel d): November-December composite; panel e): JanuaryFebruary composite. Shaded pattern interval is $0.2^{\circ} \mathrm{C}$; blue colors indicate negative values, yellow-red colors indicate positive anomalies. Contour line interval is $2 \mathrm{~mm} /$ day; negative precipitation anomalies are represented with dashed lines. The reference arrow corresponds to a wind speed of $5 \mathrm{~m} / \mathrm{s}$.

that are associated with the changes in the SST field. Figure 19a-e shows the composites obtained from the T42 version of the model for the positive phase of the IODM. The composite 
patterns have been computed by averaging the anomalies corresponding to events for which the DMI value is larger than 1.5 standard deviation.

Cold SST anomalies (shaded patterns) start to develop in the EIO in late spring (panel a), accompanied by weak south-easterlies (arrows) across the equator. During the following summer (panel $b$ ), the negative SST anomalies and the south-easterlies intensity in the EIO and positive anomalies develop in the western part across the equator. The simulated positive SST anomalies in the WIO are larger than in the observations (e.g., S99). This is probably a consequence of the model tendency to produce a weak coastal upwelling in this region (Gualdi et al., 2003), which, in turn, might be related to the weak model summer Asian monsoon (see Section 4.1). These large warm SST anomaly simulated in the WIO during July and August, is most likely the cause for the slight advance of the simulated DMI peak occurrence compared to the observations (fig. 18).

At the same time, precipitation is reduced in the southern-EIO, over the region of cold SST and near-surface divergence, and is increased in the western part of the basin, where the warmer SST is located. The anomalies peak during the northern autumn (panel c and d) and disappear during the following winter (panel e).

The life cycle of the simulated dipole mode event (in its positive phase) as depicted by the sequence of these composites is in general good agreement with the observational results of S99. A detailed discussion of the model interannual variability in the tropical Indian Ocean is given in Gualdi et al. (2003). From the results shown here, we can conclude that the model appears to capture and reproduce with reasonable accuracy all the main features of this mode of variability that characterizes the tropical Indian Ocean.

\section{Discussion and conclusions}

In this paper, we have analyzed the ability of a new coupled GCM, SINTEX, to simulate the main features of the observed climate and its dominant modes of variability, focusing in particular on the Indo-Pacific tropical region. We have also assessed the impact of increased atmospheric resolution on the coupled system, using the model with different horizontal resolution of the atmospheric component: a lowresolution (T30), a medium-resolution (T42) and a high-resolution (T106) atmospheric model.

In all model experiments, the drifts at the atmosphere-ocean interface are reasonably small. In particular in the tropical region, the drifts appear to be remarkably small for a coupled model that does not apply any flux correction. At higher latitude, especially in the North Atlantic, the drifts in SST and sea-surface salinity are more evident. This is probably due to the lack of any interactive sea-ice.

The mean state is captured reasonably well. Overall, the SST errors relative to observations (not shown) are smaller than $1^{\circ} \mathrm{C}$. Differences larger than $2{ }^{\circ} \mathrm{C}$ are found only in the equatorial upwelling regions (e.g., off the Peruvian coast) and along the western boundary currents in the extra-tropical Pacific and Atlantic.

At all resolutions, the model SST tends to be too warm in the tropical Eastern Pacific. The equatorial cold tongue penetrates too far into the West Pacific due to stronger-than-observed trade winds. These intensified trades are associated to the atmospheric model (ECHAM-4) tendency to overemphasize the Walker-type circulation in the equatorial plane (Roeckner et al., 1996). Furthermore, the simulated mean precipitation and near-surface wind indicate that the model tends to produce a double ITCZ. These model errors are common to many CGCMs and might be due both to an inadequate representation of atmospheric convection, and to a lack of simulated cloud coverage off the Peruvian coast.

The models give a realistic representation of the temperature structure at the equator in the Pacific and Indian Ocean. The equatorial thermocline slope and structure, of importance for ENSO dynamics, are generally well reproduced. Though, for the lower resolution model versions, the warm pool is eroded and the thermocline is too deep in the Central Pacific. Both these features are most likely due to the strong trades found for the T30 and T42 cases.

The simulated seasonal variation exhibits some problem in the equatorial Pacific. In the eastern equatorial Pacific, the annual cycle of the SST is underestimated compared to the obser- 
vations; whereas, the seasonal and semiannual modulation is overestimated in the Central Pacific. Although we do not have a complete explanation for these errors, we think that they might be related to the errors found in the mean state.

The ability of the model to simulate the main general features of the interannual variability in the tropical Indo-Pacific region has also been analyzed. In the Indian Ocean, the characteristics of the interannual variability simulated by the model are remarkably close to the results found from the observations (see also Gualdi et al., 2003).

In the Pacific, the modelled ENSO exhibits a variability slightly weaker than in the observations. Furthermore, the period of the simulated oscillation appears to be a bit shorter than observed, especially in the low-resolution model case. The overall timing and anomaly patterns associated with ENSO are, in general, quite close to observations (see also Guilyardi et al., 2003). However, in the T30 and T42 cases, the SST variability is too much confined to the equator. In the T106 model, on the other hand, there is a clear improvement in the structure of the SST anomaly patterns.

Finally, the increased horizontal resolution (T106) of the atmospheric component leads to some improvement, reducing the amplitude of the model bias. Furthermore, the simulated interannual variability, especially in the tropical Pacific, appears to be improved. This might be due to a better representation of the coupled air-sea processes yielded by the highresolution atmospheric component. However, a complete explanation of this result would need a much more detailed analysis, which is beyond the scope of the present paper.

\section{Acknowledgements}

The authors are indebted to Dr. J. Joachim Segschneider for helpful discussions and suggestions. They are also grateful to Mrs. Loredana Amato for technical support. This work has been supported by the European Community contract SINTEX ENV4-CT98-0714.

\section{REFERENCES}

ACHUTA RAO, K., K.R. SPERBER and the CMIP Modelling Groups (2001): El Niño Southern Oscillation in coupled GCMs, Program for Climate Model Diagnosis and Intercomparison Report n. 61, pp. 45.

BACHER, A., J.M. OBerHUber and E. ROECKNER (1998): ENSO dynamics and seasonal cycle in the tropical Pacific as simulated by the ECHAM4/OPYC3 coupled general circulation model, Climate Dyn., 14, 431-450.

Blanke, B. and P. Delecluse (1993): Low frequency variability of the tropical Atlantic Ocean simulated by a general circulation model with mixed layer physics, $J$. Phys. Oceanogr., 23, 1363-1388.

Delecluse, P., M. Davey, Y. Kitamura, S.G.H. Philander, M. SuAREZ and L. BENGTSSON (1998): Coupled general circulation modeling of the tropical Pacific, J. Geophys. Res., 103, 14,357-14,373.

FISCHER, M. and A. NAVARRA (2000): GIOTTO: a coupled atmosphere-ocean general-circulation models: the tropical Pacific, Q. J. R. Meteorol. Soc., 126, 1991-2012.

FREY, H., M. LATIF and T. STOCKDALE (1997): The coupled GCM ECHO-2, part I: the tropical Pacific, Mon. Weather Rev., 125, 703-720.

Gates, W.L., J.S. Boyle, C.C. Covey, C.G. Dease, C.M. DOUTRIAUX, R.S. Drach, M. FIORINO, P.J. GLECKLER, J.J. HNILO, S.M. MARLAIS, T.J. PHILliPS, G.L. POTTER, B.D. SANTER, K.R. SPERBER, K.E. TAYLOR and D.N. WILLIAMS (1998): An overview of the results of the Atmospheric Model Intercomparison Project (AMIP I), Bull. Am. Meteorol. Soc., 73, 1962-1970.

GuAldi, S., E. GuILYARDI, A. NAVARRA, S. MASINA and P. DELECLUSE (2003): The interannual variability in the tropical Indian Ocean as simulated by a CGCM, Climate Dyn. (in press).

GuILYARDI, E. and G. MADEC (1997): Performance of the OPA/ARPEGE-T21 global ocean-atmosphere coupled model, Climate Dyn., 13, 149-165.

GuILYARDI, E., G. MADEC and L. TERRAY (2001): The role of lateral ocean physics in the upper ocean thermal balance of a coupled ocean-atmosphere GCM, Climate Dyn., 17, 589-599.

Guilyardi, E., P. DElECluse, S. GuAldi and A. NAVARRA (2003): The role of meridional recharging in ENSO phase change, J. Climate (in press).

InNESS, P., J.M. SLingO, E. GuILYARDI and J. COlE (2003): Simulation of the Madden-Julian Oscillation in a coupled general circulation model II: the role of the basic state, J. Climate, 16, 365-382.

Kalnay, E., M. Kanamitsu, R. Kistler, W. Collins, D. DeAVEn, L. GANDin, M. IREDEll, S. SAHA, G. White, J. WoOllen, Y. ZhU, M. Chelliah, W. EBisuZaKi, W. Higgins, J. Janowiak, K. C. Mo, C. Roelewski, J. WANG, A. LEETMAA, R. REYNOLDS, R. JENNE and D. JOSEPH (1996): The NCEP/NCAR 40-year re-analysis project, Bull. Am. Meteorol. Soc., 77, 437-471.

LATIF, M., R. KLEEMAN and C. ECKERT (1997): Greenhouse warming, decadal variability, or El Niño? An attempt to understand the anomalous 1990s, J. Climate, 10, 22212239.

LEVITUS, S. (1982): Climatological atlas of the world ocean, 
National Oceanic and Atmospheric Administration Professional Paper n. 13, pp.173.

MADEC, G., P. DELECLUSE, M. IMBARD and C. LEVy (1998): OPA version 8.1 ocean general circulation model reference manual, LODYC/IPSL Technical Report, Note 11 , pp. 91.

MANABE, S. and K. BRYAN (1969): Climate calculations with a combined ocean-atmosphere model, J. Atmos. Sci., 26, 786-789.

Mechoso, M.R., A.W. Robertson, N. BARTh, M.K. DaVey, P. Delecluse, P.R. Gent, S. Ineson, B. Kirtman, M. Latif, H. Le Treut, T. NAgal, J. D. Neelin, S.G.H. Philander, J. Polcher, P.S. Schopf, T. StOCKDAle, M.J. Suarez, L. Terray, O. Thual and J.J. Tribbia (1995): The seasonal cycle over the tropical Pacific in coupled ocean-atmosphere general circulation models, Mon. Weather Rev., 123, 2825-2838.

MorCRETTE, J.J. (1991): Radiation and cloud radiative properties in the European centre for medium range weather forecasts forecasting system, J. Geophys. Res., 96, 9121-9132.

NORDENG, T.E. (1994): Extended versions of the convective parametrization scheme at ECMWF and their impact on the mean and transient activity of the model in the Tropics, European Center for Medium Range Weather Forecasts, Research Department, Reading, U.K., Technical Memorandum n. 206, October 1994, pp. 41.

Philander, S.G.H. (1990): El Niño, La Niña and the Southern Oscillation (Academic Press Inc., San Diego, California), pp. 293.

RASCH, P.J. and D.L. WiLliAMSON (1990): Computational aspects of moisture transport in global models of the atmosphere, Q. J. R. Meteorol. Soc., 116, 1071-1090.

RAYNER, N.A., D.E. PARKER, P. Frich, E.B. HORTON, C.K. Folland and L.V. AleXANDER (2000): The HadISSTglobal sea-ice and sea-surface temperature dataset, 1871-1999, Hadley Centre Technical Note n. 17.

RoECKNER, E. and coauthors (1996): The atmospheric general circulation model ECHAM-4: model description and simulation of present-day climate, Max-PlanckInstitut für Meteorologie Report n. 218, pp. 90.
SAJI, N.H., B.N. GOSWAMI, P.N. VINAYACHANDRAN and T. YAMAGATA (1999): A dipole mode in the tropical Indian Ocean, Nature, 401, 360-363.

STENDEL, M and E. ROECKNER (1998): Impacts of horizontal resolution on simulated climate statistics in ECHAM-4, Max-Planck-Institut für Meteorologie Report n. 253, pp. 57.

StOCKDAle, T.M., A.J. BusAlaCCHI, D.E. HARRISON and R. SEAGER (1998): Ocean modelling for ENSO, $J$. Geophys. Res., 103, 14,325-14,356.

TERRAY, L. (1998): Sensitivity of climate drift to atmospheric physical parameterizations in a coupled ocean-atmosphere general circulation model, J. Climate, 11, 16331658.

TIEDTKE, M. (1989): A comprehensive mass flux scheme for cumulus parametrization in large-scalemodels, Mon. Weather Rev., 117, 1779-1800.

Trenberth, K.E., G.W. Branstator, D. Karoly, A. KumAR, N.-C. LAU and C. ROPElEWSKI (1998): Progress during TOGA in understanding and modeling global teleconnections associated with tropical sea surface temperatures, J. Geophys. Res., 103, 14,29114,324 .

Valcke, S., L. Terray and A. Piacentini (2000): The OASIS coupler user guide version 2.4, Technical Report, TR/CMGC/00-10, CERFACS.

VENZKE, S., M. LATIF and A. VILLWOCK (2000): The coupled GCM ECHO-2, part II: Indian Ocean response to ENSO, J. Climate, 13, 1371-1383.

WALKER, G.T. and E.W. BLISS (1932): World weather, V, Mem. R. Meteorol. Soc., 4, 53-84.

Washington, W.M., A.J. Semtner JR., G.A. MeEhl, D.J. KNIGHT and T.A. MAYER (1980): A general circulation experiment with a coupled atmosphere, ocean and sea ice model, J. Phys. Oceanogr., 10, 1887-1908.

Webster, P.J., A.M. Moore, J.P. LoschnigG and R.R. LEBEN (1999): Coupled ocean-atmosphere dynamics in the Indian Ocean during 1997-98, Nature, 401, 356-360.

XIE, P. and P.A. ARKIN (1996): Analyses of global monthly precipitation using gauge observations, satellite estimates, and numerical model predictions, J. Climate, 9 , 840-858. 